Illinois State University

ISU ReD: Research and eData

Theses and Dissertations

$4-1-2021$

\title{
Who Said It First?: Linguistic Appropriation Of Slang Terms Within The Popular Lexicon
}

Rachel Elizabeth Laing

Illinois State University, relaing2016@gmail.com

Follow this and additional works at: https://ir.library.illinoisstate.edu/etd

Part of the Communication Commons

\section{Recommended Citation}

Laing, Rachel Elizabeth, "Who Said It First?: Linguistic Appropriation Of Slang Terms Within The Popular Lexicon" (2021). Theses and Dissertations. 1385.

https://ir.library.illinoisstate.edu/etd/1385

This Thesis is brought to you for free and open access by ISU ReD: Research and eData. It has been accepted for inclusion in Theses and Dissertations by an authorized administrator of ISU ReD: Research and eData. For more information, please contact ISUReD@ilstu.edu. 


\section{WHO SAID IT FIRST?: LINGUISTIC APPROPRIATION OF SLANG TERMS WITHIN THE POPULAR LEXICON}

\section{RACHEL E. LAING}

65 Pages

Linguistic appropriation is an area of study that has been under-researched, even as it has become all the more relevant due to the rapid dissemination of slang and linguistic trends during the digital age. There are clear ties shown between individuals' and groups' identity and language. This study specifically examines the appropriation of African American Vernacular English (AAVE) and LGBT language by creating an Acceptability of Appropriation scale and assessing potential relationships between linguistic appropriation, intercultural tolerance, and LGBT tolerance. These results are then examined through the lens of the communication theory of identity (CTI) and potential identity gaps that may arise from groups using slang that does not belong to them. Implications of the study, limitations, and future research are discussed.

KEYWORDS: linguistic appropriation; communication theory of identity; CTI; intercultural tolerance; LGBT tolerance; AAVE; cultural appropriation 
WHO SAID IT FIRST?: LINGUISTIC APPROPRIATION OF SLANG TERMS WITHIN THE POPULAR LEXICON

RACHEL E. LAING

\author{
A Thesis Submitted in Partial \\ Fulfillment of the Requirements \\ for the Degree of \\ MASTER OF SCIENCE \\ School of Communication \\ ILLINOIS STATE UNIVERSITY
}


Copyright 2021 Rachel E. Laing 
WHO SAID IT FIRST?: LINGUISTIC APPROPRIATION OF SLANG TERMS WITHIN THE POPULAR LEXICON

RACHEL E. LAING

COMMITTEE MEMBERS:

John R. Baldwin, Chair

Kevin R. Meyer

Lindsey J. Thomas 


\section{ACKNOWLEDGMENTS}

This has been quite the long road, and I couldn't be more grateful to all the people that helped me along the way. First and foremost, I need to thank my chair, Dr. Baldwin, for being endlessly patient with me throughout this project and believing in me when I felt like I couldn't finish. Dr. Thomas and Dr. Meyer, thank you both for your contributions and guidance which made this a much better thesis than it was at the start. An enormous thank you to Alyssa Hernandez, my forever roommate and best friend who's supported me like no other, as well as

Frankie, Kameron, Kiah, and Nick. My family have always been my biggest supporters, and without them I never would have finished this thesis or probably grad school at all. And finally, a big thanks to Dr. McKenna-Buchanan, who told me I was smart enough to go to grad school in the first place.

R. E. L. 


\section{CONTENTS}

Page

ACKNOWLEDGMENTS

TABLES

CHAPTER I: STATEMENT OF THE PROBLEM 1

CHAPTER II: REVIEW OF LITERATURE

$\begin{array}{ll}\text { Cultural Appropriation } & 5\end{array}$

$\begin{array}{ll}\text { Appropriation of African American Language } & 10\end{array}$

$\begin{array}{ll}\text { AAVE } & 10\end{array}$

$\begin{array}{ll}\text { Appropriation of AAVE } & 12\end{array}$

Appropriation of LGBT Culture and Language 16

$\begin{array}{ll}\text { LGBT culture } & 16\end{array}$

$\begin{array}{ll}\text { LGBT language } & 18\end{array}$

$\begin{array}{ll}\text { Theoretical Perspectives } & 21\end{array}$

$\begin{array}{ll}\text { Communication Theory of Identity } & 21\end{array}$

$\begin{array}{ll}\text { Basic principles } & 22\end{array}$

$\begin{array}{ll}\text { Identity gaps } & 23\end{array}$

Language, Power, and Identity 25

$\begin{array}{ll}\text { Language Borrowing } & 26\end{array}$

$\begin{array}{ll}\text { The Current Study } & 28\end{array}$

$\begin{array}{lr}\text { Conclusion } & 29\end{array}$

$\begin{array}{ll}\text { CHAPTER III: METHODS } & 31\end{array}$

$\begin{array}{ll}\text { Participants } & 31\end{array}$ 
$\begin{array}{ll}\text { Data Collection } & 31\end{array}$

$\begin{array}{ll}\text { Procedures } & 31\end{array}$

$\begin{array}{ll}\text { Measures } & 32\end{array}$

Willingness to Appropriate $\quad 32$

Tolerance Measures $\quad 32$

$\begin{array}{ll}\text { Data Analysis } & 33\end{array}$

$\begin{array}{ll}\text { Conclusion } & 34\end{array}$

CHAPTER IV: RESULTS

Exploratory Factor Analyses 35

$\begin{array}{ll}\text { Tests of Difference } & 37\end{array}$

$\begin{array}{ll}\text { Correlations } & 38\end{array}$

$\begin{array}{ll}\text { Conclusion } & 39\end{array}$

$\begin{array}{ll}\text { CHAPTER V: DISCUSSION } & 40\end{array}$

$\begin{array}{ll}\text { Summary of Findings } & 40\end{array}$

$\begin{array}{ll}\text { Theoretical Implications } & 41\end{array}$

$\begin{array}{ll}\text { Practical Implications } & 45\end{array}$

$\begin{array}{ll}\text { Limitations } & 45\end{array}$

$\begin{array}{ll}\text { Future Research } & 46\end{array}$

$\begin{array}{ll}\text { Conclusion } & 47\end{array}$

$\begin{array}{ll}\text { REFERENCES } & 49\end{array}$

APPENDIX: SURVEY ITEMS $\quad 62$ 


\section{TABLES}

Table

Page

$\begin{array}{ll}\text { 1. AAVE slang terms } & 15\end{array}$

2. LGBT slang terms 21

3. Factor loadings for acceptability of appropriation scale 36

4. Factor loadings for use of slang scale 37

5. Bivariate correlations of scaled items 39 


\section{CHAPTER I: STATEMENT OF THE PROBLEM}

Language is an ever-evolving medium, with new words constantly being added to the popular lexicon. Content words, those that carry the fundamental meaning of a sentence, are considered part of the open class of words, meaning that new words may be freely added (Clark \& Clark, 1977). In fact, according to the Global Language Monitor, there are approximately 14.7 new English words created each day, and roughly 1,000 words are added to the dictionary each year (Admin, 2017; Bodle, 2016).

In general, there are five ways that new words are created: adding prefixes or suffixes, compounding (combining two words), changing a word's grammatical class, or infixing, where something is added to the middle of a word, usually for emphasis (Ellis, 1999). While less formal, huge contributors to the growing lexicon are clippings, portmanteaus, and slang terms. Slang itself is a clipped term, meaning shortened language. Mattiello (2005) defines slang by saying, first, that it is "the restricted speech of marginal or distinct subgroups in society, and, second, that it is a quite temporary, unconventional vocabulary characterized primarily by connotations of informality and familiarity" (pp. 10-11). Though frowned upon by some, slang is a constant source of new language. Walt Whitman (1885) was a proponent of slang, saying that slang "is the wholesome fermentation or eructation of those processes eternally active in language, by which froth and specks are thrown up, mostly to pass away; though occasionally to settle and permanently crystallize" (pp. 431-432). People's fascination with the evolution of language through slang is well documented. B. H. Hall began one of the first collections of slang specific to schools in 1856, and Willard Gore created "perhaps the most scholarly nineteenth-

century study of student slang” in 1895 (Dundes \& Schonhorn, 1963, p. 163). Slang is inherently 
communicative, as all aspects of language are ways to mark and communicate one's identity as well as transfer meaning of some sort.

Social media and the age of rapid information sharing have only made the evolution of slang terms quicker and more prominent. Zhang et al.'s (2016) study showed that popular attention in the early stage of propagation of Internet slang resulted in better circulation of slang terms than participation of opinion leaders, showing that widespread use of new slang terms on the Internet is common and one of the most prominent ways that these terms take hold.

One of the major hotbeds for online trends is "Black Twitter," a term coined by Sicha (2009) to refer to how Black usage of Twitter sometimes dominates the site's discourse. Black Twitter also follows Wilson's characterization of Black discursive style online, broken down by Brock (2012): “1) A culturally relevant hashtag (cultural specificity); 2) Network participation (either a comment or a retweet) by tightly linked affiliates (homophily); 3) Viral spread to reach 'trending topic' status (propagation)” (p. 534). While Black Twitter is observed largely through trending hashtags, there are also words and phrases or jokes that trend without the use of hashtags, even leading to the creation of a popular Reddit page called "BlackPeopleTwitter." where members can post screenshots of "exceptionally hilarious and insightful social media posts made by Black people." The site administrators state, "We welcome all people who want to laugh with us to enjoy and contribute" (BlackPeopleTwitter, n. d.).

Because social media are available for anyone with Internet access to interact with, trends that begin on Black Twitter are often co-opted by other users. This trend of mimicry exists not only on social media, but in day-to-day life as well. Individuals in the dominant group hear others use slang terms that they have not heard before, often those that exist in African American Vernacular English (AAVE), and increasingly from the lesbian, gay, bisexual, and transgender 
(LGBT) community, and begin to use them. This can often lead to a misuse of the words, as outgroup members who overhear or see the words being used do not have a natural fluency in the dialect; thus they either create a different meaning for the word or misuse a term, phrase, or joke within the mainstream so that these new definitions become what is popularly recognized. As this transformation occurs, original users of the words may begin to feel distanced from these terms and discontinue their use of them, relinquishing parts of their language that they may feel a cultural connection with, especially considering the ways that language and identity are interconnected. Members of the dominant culture may not recognize or appreciate the origins of these words that they use or not care, causing their use of the terms to fall under cultural appropriation. If, however, members of the dominant culture are aware of and respect the origins of the term, it can be viewed instead as cultural appreciation.

Language and the way people communicate form the social reality in which everyone exists, and these forms of communication influence how people interact with each other, as well as their perceptions of themselves and others (Luckmann, 2013). As social reality is constructed in communicative interactions, individuals acquire knowledge of this reality through repetition of these communicative interactions, building their reality and knowledge base from repeated exchanges. Symbolic interactionism suggests that humans act towards things based on the meanings they have for the things, where the meanings arise from social interaction; these meanings are then modified as individuals go through a self-reflective process and interact with others, ultimately allowing humans to create the world of experience that they inhabit (Denzin, 2004). The different connotations that things have for different people are influenced by a "circuit of culture" where the meanings are influenced by mass media, and identities can be broken down into cultural categories (du Gay et al. 1997). By using certain language, dialects, or 
speech patterns, individuals within a community can form bonds and influence their own reality by using these repeated messages. When those from outside a community or group use these patterns or dialects, they can fracture the sense of security or reality that the community holds. By gathering data on participants' willingness to use slang terms from groups or cultures that they do not belong to, as well as assessing their intercultural and LGBT tolerance, this study will explore the relationship between levels of tolerance and perceived acceptability of appropriation. In addition, the communication theory of identity will be applied, specifically looking at the formation of identity gaps and how the usage of appropriated language intersects with participants' intercultural and LGBT tolerance. In particular, I will examine the correlation between intercultural tolerance and the acceptability of using slang terms derived from AAVE or LGBT language, the correlation between LGBT tolerance and the acceptability of using these slang terms, as well as any difference between levels of acceptability from different demographic groups. This can help understand the different likelihoods of people using words from AAVE or LGBT origins in terms of cultural appropriation or appreciation. 


\section{CHAPTER II: REVIEW OF LITERATURE}

\section{Cultural Appropriation}

Cultural appropriation, defined by Arewa (2017) as "cultural borrowing that is in some way inappropriate, unauthorized, or undesirable" (p. 26), is a concept that has become more and more prevalent over the past several years, especially in popular press articles. Elliot (2017) posited that we should move away from the politicized term "appropriation" and instead refer to it as "cultural misrepresentation and miseducation" (p. 43). Wanner (2016) defined it as "the taking of an original idea by members of a dominant group from a minority without acknowledgement, and insidiously refashioning it, so that said idea appears as if it had always belonged to the dominant group" (p. 78). Popular press articles break the term down as "when someone adopts something from a culture that is not his or her own - a hairstyle, a piece of clothing, a manner of speaking, even a type of exercise (yoga, for example)" ("Cultural Appropriation,” 2018, para. 9). Most of the information on appropriation and language appropriation especially comes from the area of pop culture instead of academic research. The lack of academic research is disappointing, but it is important to remember that pop culture influences our face-to-face interactions. An important distinction is that cultural appropriation is an active process of making something one's own, as opposed to mere exposure to elements of another culture (Rogers, 2006). Many different types of appropriation exist. Young (2008) describes cultural appropriation in art, while Arewa points to the appropriation of African American music and culture in America by both celebrities and everyday people.

Where many people differ is on the question of where cultural appropriation is appropriate, if indeed it ever is. Often, people have a difficult time trying to determine what is cultural appropriation and what is not. Mercado, writing for Bustle in 2017, compiled a list of 
seven things that are commonly not realized as cultural appropriation. The list included "authentic" food, the use of African American Vernacular English (AAVE), festival trends such as Native American headdresses and bindis, and themed parties that rely on stereotypes of other cultures. Many times, cultural appropriation, especially that which occurs in the United States, is easily visible and can be understood as offensive, even if the observer of the appropriation does not take personal offense. But there is a spectrum of cultural borrowing, one that ranges from cultural exchanges and appreciation to appropriation. Young and Haley (2009) work to understand how cultures remain porous, with different cultures being constantly influenced by each other: At what point is the fluidity of culture acceptable, especially in art and literature, and when has it gone too far? Young (2005) points to a constant exchange of ideas and the concept of profound offensiveness: In many instances, cultural appropriation is objectionable but not profoundly offensive enough to be wrong due to cultural fluidity.

This attitude towards appropriation and art, though, is markedly different than the reactions of many people of color to appropriation in mainstream culture. Due to cultural imperialism, where one culture, usually seen as Western culture, conquers and reorganizes another culture into an imperial culture, a certain amount of assimilation takes place so the nondominant culture takes on the appearance of the dominant culture (Jin, 2017). In response to cultural imperialism comes cultural resistance, where members of the minority culture take elements of the dominant culture and repurpose them as a form of resistance, such as the reclamation of derogatory words and slurs, giving the members of the marginalized culture a sense of agency (Rogers, 2006).

Cultural appropriation always involves a marginalized group having something borrowed or taken from them by a dominant group or culture in a way that many members of the 
marginalized group find offensive or do not agree with. As a whole, that marginalized group does not get a choice in the matter, and when members speak up, they are often ignored or mocked by the dominant culture. This often occurs in cases of fashion and with a sense of ignorance - many do not realize that what they are doing, wearing, or consuming can be seen as insensitive or hurtful to others, with such actions becoming cultural exploitation and often commodification (“Cultural Appropriation,” 2018; Rogers, 2006). Cultural products that are "wrongfully exploited for financial gain" become commodified by the dominant culture, allowing corporations to profit off of the cultural capital of minority cultures (Ziff \& Rao, 1997, p. 14). For example, in 1907 the manufacturing company Royal Doulton introduced porcelain featuring a design called "Maori Art," using a pattern generically known as "koru' (Shand, 2002). In the following years, similar designs have been used in New Zealand for things like stamps and government department letterheads, and Air New Zealand has used a koru design on its airplanes since the 1960s. Various fashion designers in New Zealand and beyond have used koru designs that people describe as "tribal," all while indigenous people do not receive profits from a symbol that is theirs, and local artisans cannot compete with mass production from companies. Gulati-Partee and Potapchuk (2014) refer to White culture as "the dominant, unquestioned standards of behavior and ways of functioning embodied by the vast majority of the institutions in the United States" (p. 27). It cannot be appropriated or taken from in a negative way by members of other cultures due to the power differential between Whites as the dominant majority and all of minority groups.

Celebrities are frequently accused of cultural appropriation due to their being in the public eye, making their mistakes much more noticeable. Justin Bieber, Madonna, Katy Perry, and Karlie Kloss have all been taken to task for their use of fashion, accessories, and hairstyles 
that do not belong to them or their culture. In 2016, Bieber wore his hair in dreadlocks for a short time, fielding criticism on social media and denying that he "want[s] to be Black," defending his look as just a hairstyle before buzzing his head less than a month later (McFadden, 2016). Madonna wore clothing and jewelry including a horned headdress belonging to North Africa's Amazigh people to the 2018 MTV Video Music Awards, causing controversy as people disagreed whether or not she was disrespecting the culture or appreciating it, as the markets in Morocco are full of similar pieces to the ones Madonna wore ( $\mathrm{Lu}, 2018)$. Perry gave a performance at the American Music Awards in 2013 that was modeled after stereotypes of Asian women, and Kloss wore a Native American headdress during the 2012 Victoria's Secret Fashion Show, along with a Native American-inspired lingerie set (Cowles, 2012; Feeney, 2013). Both women later apologized (though Bieber did not), but instances of cultural exploitation like these still happen frequently. Recently, LSPIRG started their "I Am Not a Costume" campaign, advocating for the end of Halloween costumes that are racist or transphobic (LSPIRG, n.d.). When retailers profit off costumes that perpetuate harmful negative stereotypes against marginalized cultures, the cycle of cultural degradation and unequal power relations continues unchecked. When White people adopt fashions or hairstyles from other cultures, they are often praised for being cool or trendy, while these things remain too ethnic for people of color (Johnson, 2015). When one tells members of a non-dominant culture that they cannot partake in their own culture for fear of being too ethnic or too other, this removes power from them and constrains their self-expression, and parts of the culture that White people want to partake in are commodified. Members of the originating culture can no longer comfortably use aspects of their culture, while the businesses in the dominant culture profit off these stolen ideas or products. For example, Riley and Carpenter (2016) discuss what they term "Indian appropriation," where the 
U.S. legal system normalized and assisted the taking of all things Indian for non-Native use, including lands, sacred objects, and fashions.

Cultural exchange, on the surface, sounds like two cultures engaging in an equal trade:

One culture gives something to the other, and the act is reciprocated. Rogers (2006) defines it as "the reciprocal exchange of symbols, artifacts, rituals, genres, and/or technologies between cultures with roughly equal levels of power" (p. 477). Uwujaren (2013) gives an example of cultural exchange, relaying the experience of her Nigerian sister's marriage to a White man, where both the bride and groom changed into traditional Nigerian clothing partway through the ceremony. She views the event as exchange due to the groom's not treating the outfit like a costume or acting as if it was strange in any way, but rather simply being invited to partake in the bride's culture while also not overstaying his welcome. Cultural appreciation falls under the same umbrella; Estrada (2017) defined it as "having a genuine or authentic interest in a culture; in learning about the history (the good and bad), the people and its perspectives and building relationships with members of that culture on the basis of that understanding" (para. 5). Cultural appreciation asks an individual to understand where the behavior, fashion, or hairstyle they are using or partaking in comes from, what it means, and that culture's attitudes towards others partaking in it. Tran (2016) asks five questions to determine if someone is partaking in cultural appropriation; if not, they are likely demonstrating appreciation instead. Tran says to ask to what ethnic, cultural, or racial group the practice belongs; how that group is oppressed; how the person benefits from partaking in the culture; why the practice could make someone uncomfortable; and what makes it possible for the person to partake in the practice or artifact. If those questions are met with positive answers, the outcome is likely to be that of cultural appreciation. 


\section{Appropriation of African American Language}

\section{AAVE}

Rickford and Rickford (2000) refer to AAVE as Spoken Soul, a term first used by Claude Brown in 1968. It is commonly believed that AAVE grew out of the African languages that came to America with slaves during the $17^{\text {th }}$ century and subsequently went through the process of pidgin, creolization, and decreolization, called the creole hypothesis (Johnson, 2002). It is also hypothesized that some linguistic features of AAVE that are widely known today came into existence during the Great Migration of the $20^{\text {th }}$ century, as Blacks moved into segregated urban areas and further developed AAVE. Bereiter and Englemann (1966) posited the deficit hypothesis, claiming that AAVE grew out of cultural deprivation and a lack of maturity, but this was soundly disproved throughout the years. An aggregation of linguistic scholars' reports notes that AAVE contains the universal principles of language systems, is rule-governed and logical, and contains many elements that run parallel with language systems from West Africa and the Caribbean, suggesting a common origin and supporting the creole hypothesis (Taylor, 1998). In 1997, the Linguistic Society of America issued a statement that acknowledged AAVE as being systematic and rule-governed, calling it a vernacular speech variety. The systematic process of AAVE can be seen in the basic building blocks of all kinds of language: phonologically, AAVE has many unique parts, including 1- and r-lessness (assimilating an /1/ or /r/ sound to a preceding vowel), the phonological contraction of going to into gon, the suprasegmental forward stress of multisyllable words (po-lice stressed as PO-lice), and the axe trend (ask is pronounced as axe or ass) (Johnson, 2000). In terms of syntax and morphology, more characteristic traits are zero copula or copula deletion (the absence of is or are), multiple negation or negative concord, invariant be (either leaving out the contractual forms of will or would, or the habitual be), and a 
lack of passive voice. AAVE also includes elements such as tonal semantics, meaning that tonal aspects such as intonation, cadence, pitch, stress, and volume imbue different meanings into discourse.

Rickford and Rickford (2000) give many reasons for the tenacity of AAVE in the face of discrimination, as people from the dominant language group often see the language as inferior or “improper” English:

The reasons for the persistence and vitality of Spoken Soul are manifold: It marks Black identity; it is the symbol of a culture and a life-style that have had and continue to have a profound impact on American popular life; it retains the associations of warmth and closeness for the many Blacks who first learn it from their mothers and fathers and other family members; it expresses camaraderie and solidarity among friends; it establishes rapport among Blacks; and it serves as a creative and expressive instrument in the present and as a vibrant link with this nation's past. (p. 10)

Labov (2003) notes that AAVE currently is not an endangered language variety: in fact, it has grown and developed, diverging from Standard English (SE) due in part to cyclical residential segregation and poverty. If residential segregation significantly decreases, Labov worries that AAVE could lose distinctiveness as a dialect. However, a 1998 study comparing the codeswitching of middle-class users of AAVE and middle-class German-English bilingual residents showed that AAVE was not moving towards linguistic assimilation into dominant society, though the bilingual speakers were (Carter, 2013). Mufwene (2017) also argues that AAVE functions as an ethnic identity marker and is unlikely to disappear due to lessened residential segregation. A study observing AAVE-speaking and U.S. Latino populations in multi-ethnic communities showed that certain grammatical forms of AAE were likely to show up in the 
speech of the U.S. Latinos, though slightly modified for their own use (Carter, 2013). In this case, the original speakers of AAVE did not change their speech patterns to include aspects of the U.S. Latinos' speech.

Recently, one of the largest challenges faced by speakers of AAVE is how educators view the language in the classroom. Due to the belief among many educators that AAVE is an improper form of SE, children may be punished or continually corrected for speaking or writing in AAVE in the classroom. Even though AAVE is often treated as an inferior language in educational settings, it has not seen a decline in usage. This is partly due to speakers' ability to codeswitch, that is, the ability to "choose the language variety appropriate to the time, place, audience, and communicative purpose" (Wheeler \& Swords, 2004, p. 471). According to Whitney (2005), demonstrating and encouraging codeswitching in the classroom is an invaluable way to help students develop a fluency in both AAVE and SE. This helps students to retain their knowledge and pride in AAVE but be able to switch into SE when necessary. Clearly, the history of AAVE is rich, and the language has continued to exist and develop since its origination in the $17^{\text {th }}$ century, resisting assimilation into SE.

\section{Appropriation of AAVE}

Rap and hip-hop culture have never been exclusively Black, but according to Cutler (2003), "The urban African American experience is central to its message" (p. 3) due to rap's relatability of the Black experience of marginalization and racism toward many others of marginalized groups. However, the music, language, and fashion of this culture are highly accessible and commodified, leading to discourses of authenticity and who should be allowed within the culture. Cutler (1999) studied a White male teenage family friend, Mark, recording one-on-one interviews and group sessions involving his friends in 1995-1996, observing his use 
of AAVE that appeared inauthentic. His earlier use of AAVE at ages 13-14 reflected a sense of identification with African Americans, according to Cutler, but at age 15 he changed schools and began expressing resentment towards Black peers for behaviors he perceived as cliquey. Though he began to distance himself from African Americans, he still actively used AAVE and consumed parts of hip-hop culture. This attitude is reported by Cutler: "Many young Whites feel they have the right to appropriate the hip-hop look and language, and that Black adolescents who oppose them are racists" (p. 436). When he reached the age of 19, Mark had entirely changed his appearance, taking on a more clean-cut, preppy look instead of his hip-hop style, while still frequently using AAVE phonology and hip-hop terms. Jacobs-Huey (1997) reported on a graduate student who had, in many ways, a technically correct usage of AAVE, but was still seen as performing a stereotyped version of AAVE by his Black peers, leading to his language usage being seen as inauthentic.

The language used by most rappers is AAVE, African American English, or Black English, even if the speaker is not Black. In Cutler's (2003) study of 35 white hip-hoppers, she studied the concept of authenticity within hip-hop culture, finding that white hip-hoppers were sensitive to the concept of authenticity due to the importance placed on realness within the culture. However, their adaptation of AAVE, and in particular what Cutler deemed hip-hop speech style seems contrary to the cultural importance of keeping it real. While some white hiphoppers remained highly aware of their own privilege and worked to downplay racial differences, others contributed to the erasure of blackness within hip-hop culture and reinforced their own white privilege.

A modern example of the cooption of AAVE by a white rapper is the Australian rapper Iggy Azalea. Eberhardt and Freeman (2015) analyzed 48 songs by Azalea, as well as five radio 
interviews with the rapper that were at least 10 minutes long, to get an accurate idea of her use of AAVE in casual conversation and while rapping. They found that, overall, Azalea appears to use AAVE “overzealously as a central way of positioning herself within hip-hop" (p. 317). While she does make direct reference to her whiteness and Australian identity within her music, Azalea uses phonological features of AAVE heavily while rapping. For example, in Eberhardt and Freeman's study of her music and interviews, within songs Azalea has a nearly $75 \%$ rate of copula deletion, while in conversation the rate is virtually $0 \%$. Complex's review of her first fulllength album criticizes her delivery within her raps: "Her voice, in essence, sounds like a put-on version of a particularly technical rapper from the American South" (Drake, 2014, para. 9). This leads to a highly inauthentic presentation of AAVE, signaling an appropriation of a language dialect and speech style to add authenticity to her raps that does not carry over into her regular speech.

While non-Black users of AAVE can often have an inauthentic affect, there are cases where these individuals do have an authentic usage of AAVE. Sweetland (2002) reported on a 23-year-old white female, Delilah, who lived in an overwhelmingly Black neighborhood for her entire life, obtaining her linguistic patterns from engaging in conversation throughout her life instead of from exclusively listening to hip-hop and attempting to imitate what she heard. Authenticity in non-Black use of AAVE seems largely to come from interaction and immersion within Black culture, resulting in a lived experience. Bucholtz's (1999) study subject, called Brand One, projected "an urban youth identity that aligns him culturally with African American youth" (p. 453) and used what Bucholtz termed cross-racial AAVE. Cross-racial AAVE is usually seen by speakers of AAVE as an inauthentic but acceptable use of AAVE by members of the outgroup. Jacobs-Huey's (1997) White subject was largely seen as an inauthentic speaker of 
AAVE by his Black peers. Even though he was well versed in the dialect, he lacked the awareness of when to use AAVE and SE, frequently using AAVE in classroom settings where his Black peers largely used SE. This unawareness of when to codeswitch marked him as an inauthentic speaker in face-to-face interactions, though $92 \%$ of survey respondents listening only to a recording of his speech categorized him as African American.

There is little academic research directly on the process of linguistic appropriation and assimilation of AAVE terms into the popular lexicon. Hill (2008) notes that "African American English is the single most important source for new slang (and, eventually, unmarked everyday colloquial usage)" (p. 169). Though not comprehensive, Table 1 contains a list of popular slang terms compiled from both academic and popular press articles that are considered to originate from AAVE.

\section{Table 1}

AAVE Slang Terms

\begin{tabular}{cc}
\hline Term & Definition \\
\hline hella & extremely \\
turnt/turn(ed) up & excited or drunk \\
ratchet & similar to ghetto; letting loose; messy \\
bae & baby, babe \\
aight/aite & all right \\
on point/fleek & exactly right \\
salty & petty \\
thirsty & wants or needs something \\
cool & impressive \\
\hline
\end{tabular}




\section{Appropriation of LGBT Culture and Language}

\section{LGBT culture}

With the rising popularity of RuPaul's Drag Race, which made the switch from Logo (a television channel mainly focused on queer content) to VH1 in 2017, more than doubling its viewership, queer culture has had more visibility in mainstream culture (Collins, 2015; Petski, 2017). However, this visibility has led to an influx of appropriation or invasion of queer spaces and linguistic trends. Gay bars, which once served as a haven for the LGBT community to be away from the dominant heterosexual culture, have been increasingly overrun by straight women. Miz Cracker (2015), a prominent New York City drag queen, noted this influx of usually poorly-behaved women into these spaces. Cracker is quick to note the difference between those who are respectful of queer culture and those who are not, saying that a respectful straight woman, "versed in the semiotics of gayness" (para. 6), is generally not seen as a problem. Instead, the issue is "straight people behaving badly in gay bars, arriving in balance-tipping throngs and turning pseudo-sex clubs into silly dance halls, drag shows into disrespectful free-

for-alls, and quiet lounges into scream-filled shot dispensaries" (para. 9). Bachelorette parties are especially seen as problematic, with women behaving disrespectfully during drag shows in venues that used to be seen as queer spaces.

At Darcelle XV Showplace in Portland, Oregon, the atmosphere has shifted from a decidedly queer space to one regularly filled with bachelorette parties, with straight women outnumbering the queer patrons most weekends (Shaw, 2017). Shaw noted that on one weekend when she and her partner took Shaw's sister to Darcelle's for her birthday, there were no fewer than 14 bachelorettes attending the drag show, and every single one, along with the rest of their parties, were white. Shaw attributed the freedom these young, straight white women feel to 
invade queer spaces to their privilege, saying: "They can just be out for a good time without ever questioning what their presence in queer space might mean for queer people. That is the very definition of privilege" (para. 11). She went on to note the dual nature of this appropriation of queer space: Not only does this phenomenon make these spaces feel unsafe for queer people, it is often doubly uncomfortable for queer people of color. This commodification of queer culture by heterosexual people is most commonly seen with drag performances, which have further been watered down into pop culture by the abduction of lip syncing into late-night TV.

Lip syncing is a prominent part of drag culture, added to many drag performances as a way to further the illusion of feminine performance (Shorey, 2017). Lip syncing rose to mainstream prominence due to RuPaul's Drag Race, where at the end of each episode two contestants are asked to lip sync against each other to determine who stays and who leaves the competition (Jones, 2017). Recent seasons of Saturday Night Live have referenced Drag Race and drag culture in general; in 2017 host Chris Pine and cast members portrayed a group of mechanics obsessed with the show, and in 2018 host John Mulaney appeared as a drag queen in a sketch called "Drag Brunch" (Saturday Night Live). In 2013, Jimmy Fallon introduced a "Lip Sync Battle" segment on The Tonight Show with Jimmy Fallon where he and a guest were pitted against each other, each lip-syncing different songs for the audience to determine a winner (Kreps, 2014). The popularity of the segment led to a spinoff show, Lip Sync Battle, which premiered on Spike in 2015 as the channel's most-viewed premiere ever (Walsh, 2017). The show is a clear rip-off of drag culture's art of lip syncing; both RuPaul Charles and Michelle Visage, a judge on Drag Race and a known presence in drag culture, have denounced the show, with Charles saying, "It's a poor ripoff of our show. Regular, straight pop culture has liberally lifted things from gay culture as long as I can remember" (Jung, 2016, para. 13). This is an 
important, repeated observation: Mainstream, popular culture frequently grabs for things that do not belong to it, taking pieces of other cultures and molding them in a way that removes a sense of authenticity.

Within highly commodified cultures, marginalized groups see aspects of their culture removed from their grasp and molded into something that fits within the dominant culture, with many important aspects removed. bell hooks spoke scathingly on the subject:

Within commodity culture, ethnicity becomes spice, seasoning that can liven up the dull dish that is mainstream White culture. Cultural taboos around sexuality and desire are transgressed and made explicit as the media bombards folks with a message of difference no longer based on the White supremacist assumption that "blondes have more fun." (hooks, 1992, p. 21)

When aspects of a culture are removed from their appropriate context, they become watered down and ultimately disrespected by the mainstream culture. In general, the dominant culture is White, cisgendered, and heterosexual, and freely takes from nondominant cultures, including the queer and African American communities.

\section{LGBT language}

Many communities and minorities have their own dialect or language, and the idea of gay/queer slang is no different. The original gay language grew out of Polari, which Simes (2005) defines as a pidgin Italian and Spanish first used by circus performers, later adopted by gay actors, and eventually becoming a part of British gay language, though use has subsided after the 1980s. As he examined two glossaries of gay language from the $20^{\text {th }}$ century, Simes notes that "it emerges clearly from these expressions that ... homosexuals use a distinctive jargon among themselves" (p. 15), before using 122 pages to provide historical lexicographical 
commentary on the two glossaries, giving plenty of examples to show how the words were used in the $20^{\text {th }}$ century. Many words that appear in the glossaries are still used to this day, even in mainstream English; an example of a Polari word still in circulation is zhuzh, also spelled zhoosh or tzhuj (phonetically/zoz/, pronounced onomatopoeically). The word gained widespread popularity due to Carson Kressley from the original Bravo show Queer Eye for the Straight Guy, meaning "a slight improvement or adjustment" (Merriam-Webster, 2018, para. 5). In modern drag culture the word has become jush, as drag queen Jasmine Masters (2017) uses it for a filler word: “we just use the word 'jush' for anything ... I'm getting my jush making a video, you can get your jush and watch me" (Jasmine Masters). Due to the popularity of Masters after appearing on RuPaul's Drag Race, her use of jush has become more common in the dominant lexicon.

Luu (2018) worries that, "though the unique speech of drag queens emerged as a way to show belonging in a marginalized subculture, it may soon belong to a more mainstream audience who may not even be aware of its long, unspeakable history" (para. 21). This fear of linguistic appropriation is not new: A Mic article noted a list of words/phrases that originated in the gay community that have since crossed over to the mainstream, including "yaaasss," "serving [blank] realness," "shade," and "werk" (Turner, 2015). However, Turner was optimistic that with appropriate recognition of the words' origins would come appreciation instead of appropriation.

There is little research on the process of linguistic appropriation from the gay community, but it can be assumed that it follows a similar path of the appropriation of AAVE by the dominant culture. Language becomes adopted by the dominant culture, often used incorrectly so that the new, dominant, meaning of the words does not match the original culture's, and no longer feels as if it belongs to the original culture. This results in a constant stream of new language being developed: “There's always been a reinventing of terminology because of 
appropriation by white or straight communities ... terms repeatedly borrowed from young African American speech, for example, lose their ability to convey African American identity" (Pandell, 2018, para. 23). It is important to note, though, that there is some debate over the origin of gay slang itself: Many popular expressions emerge from drag culture, to where Pandell refers to drag as a "linguistic sponge in queer communities of color" (para. 12).

It seems as though LGBT people of color can be seen as the source of much slang that has been adapted into popular culture; those that belong to both communities have a higher chance of producing language that eventually becomes co-opted by the dominant culture. This reflects intersectionality, a term first used by Crenshaw to describe "the various ways race and gender interact to shape the multiple dimensions of Black women's employment experiences" (1991, p. 1244). The term, now expanded to refer to the "multiplicity and interactivity of social identity structures such as race, class, and gender" (Gopaldas, 2013, p. 91) at the macro-level of analysis and, at the micro-level, denotes that "every person in society is positioned at the intersection of multiple social identity structures and is thus subject to multiple social advantages and disadvantages" (p. 91). This raises the question of which group or community should be seen as the dominant originator of a term when the person belongs to both the Black and LGBT communities, potentially asking which identity a person feels is most important or dominant within themselves.

Though not comprehensive, Table 2 contains a list of slang terms predominantly used by the LGBT community, compiled from popular press articles, though with some dispute over racial origins. 


\section{Table 2}

LGBT Slang Terms

\begin{tabular}{cc}
\hline Term & Definition \\
\hline $\begin{array}{c}\text { yas/yaaaassss } \\
\text { (throwing) shade }\end{array}$ & a more emphatic "yes" \\
& sly insults that can have an element of \\
work/werk & plausible deniability \\
realness & expression of approval \\
& in drag, a biologically feminine look \\
clock & can involve any kind of "realness" \\
\end{tabular}

\section{Theoretical Perspectives}

\section{Communication Theory of Identity}

First introduced by Hecht (1993), the communication theory of identity (CTI) was conceptualized to understand identity as a communicative action where messages are exchanged in order to establish and maintain identity. Hecht noted that identity was primarily studied in the fields of psychology, anthropology, and sociology, leading to a focus on individual, role, social, and communal facets of identity. Hecht et al. (1993) stressed two ways that communication can lead to identity: First, communication can be symbolic, leading to the formation of identity by symbolic attachment through social interaction. Hecht et al. agreed with social identity theory that when individuals place themselves in socially recognizable categories, they form and reform their identities. These identities lead to expectations that in turn influence individuals' communication; thusly, identity is both internally and externally shaped due to social interactions and expectations. 


\section{Basic principles}

CTI began with eight basic assumptions that guide researchers, later expanded to 10 , which are as follows:

- Identities have individual, enacted, relational, and communal properties.

- Identities are both enduring and changing.

- Identities are affective, cognitive, behavioral, and spiritual.

- Identities have both content and relationship levels of interpretation.

- Identities involve both subjective and ascribed meanings.

- Identities are codes that are expressed in conversations and define membership in communities.

- Identities have semantic properties that are expressed in core symbols, meanings, and labels.

- Identities prescribe modes of appropriate and effective communication.

- Identities are a source of expectations and motivations.

- Identities are emergent. (Hecht, Warren et al., 2005, p. 263-264)

The first assumption of CTI discusses what Hecht referred to as the four frames of identity, which allow individuals to ascertain the "location" of a person's identity by interpreting reality through them (Hecht, 1993; Hecht et al., 1993). These frames may be examined separately or in tandem as modes of interpretation but can never exist in total isolation from one another (Hecht, Warren et al., 2005).

Within the personal frame the individual is the locus of identity, which is understood as "self-concept, self-cognitions, feelings about self, and/or spiritual sense of self-being" (Hecht, Warren et al., 2005, p. 263). In the enactment frame, the self becomes a performance carried out 
through messages from the individual. For the relational frame, relationships become units of identity through individuals' view of relationships, social roles, and themselves, allowing identity to be mutually constructed (Hecht, 1993). Finally, in the communal layer, groups also affect a person's identity, as members tend to have similar traits and form a group identity. All four layers help an individual to make sense of the world around them, including an interpenetration of - or mutual influence between - the layers that contributes to the lived experience of individuals in society. Within these layers, people choose what to emphasize,

pulling one or several aspects of their being forward, acting as organizing principles for different parts of one's life (Hecht, Jackson et al., 2005).

\section{Identity gaps}

While these layers are meant to work both together and separately, in some instances there are identity gaps in which there are discrepancies between or among the frames, especially when someone ascribes an identity to an individual that differs from the individual's perception of themself (Hecht, Warren et al., 2005, Hecht, Jackson et al., 2005). There are 11 possible identity gaps that are acknowledged as practically inevitable due to imperfect communication and relationships (Jung \& Hecht, 2004). The two most studied gaps are the personal-relational identity gap and the personal-enacted identity gap. In the personal-relational identity gap, the individual's self-view differs from their perception of others' view of them, or, in the terms of the original theory, the identity that one claims or "avows" does not match the identity that others "ascribe" to them (Collier \& Thomas, 1988). Jung and Hecht posited that the personalrelational identity gap starts with the internalization of others' views of oneself, which influences and forms a part of a person's identity regardless of how closely it may lie to the person's own self-concept. This forms the gap between the personal and relational frames. In the personal- 
enacted identity gap, an individual's enacted identity may not match with how they view themselves as a person or communicator. The larger an identity gap, the more negative effect it may have on perceptions of an individual as a communicator.

Identity gaps have been used to study a wide variety of concepts, but especially situations where gaps arise due to a person's ethnicity or sexual orientation. Drummond and Orbe (2009) studied the personal-relational and personal-enacted-relational identity gaps that occur for Black and Hispanic individuals within intraracial encounters. In the personal-relational gap, an individual is aware that others do not recognize their true nationality or ethnicity, often resulting in the questions "What are you?" or "Where are you from?" Within the personal-enactedrelational identity gap, there is a difference between how the individual sees themselves, how they present themselves to others, and the identity carried out within the person's relationships. Within this study, Drummond and Orbe found that "a gap between one's personal and enacted identities can occur when the personal identity is steeped in negative stereotypes that may deny access to the social circles he or she desires to be a part [of]” (p. 84-85).

Wadsworth et al. (2008) examined the relationship between personal-enacted and personal-relational identity gaps and international students' educational satisfaction; Jung and Hecht (2008) used CTI to understand the relationship between personal-enacted and personalrelational identity gaps and depression in Korean immigrants. Jung (2013) also investigated the significant effect personal-relational, personal-enacted, and enacted-relational identity gaps had on depressive symptoms. Nicholas (2006) included CTI and Baldwin and Hecht's layering perspective in an overview of how interdisciplinary studies can work together to study GLBTQ identity. Orbe (2004) used CTI's frames to understand how all four frames are used to negotiate the identity of first-generation college students. Identity gaps are an area of study that can help 
researchers understand what happens when an individual's four frames do not align. They have monumental effects on social interactions and outcomes and become a part of a person's sensemaking on the individual and communal levels (Hecht et al., 2005).

\section{Language, Power, and Identity}

Language, power, and identity are all closely tied together. Norton (1997) defines identity as "how people understand their relationship to the world, how that relationship is constructed across time and space, and how people understand their possibilities for the future" (p. 410). As a TESOL educator, Norton agrees with Bourdieu's insistence on second language learners' right to speak, which can also translate to anyone's right to speak their given language. Rivest et al. (2017) conclude that language is a large part of an individual's identity, equally as important as gender, race, and class. For Rassool (1998), language signifies cultural belonging, carrying cultural and symbolic power with it, becoming a building block for multi-leveled power relations. Rassool then concludes that, because language is both culturally and materially rooted, issues involving the language rights of groups of people cannot be addressed outside of a general view of society and social policy. Problems with linguistic groups cannot exist outside of larger societal issues that they may be facing.

In discussing the relationship between language and power, Wodak (2012) says that "language (and other symbolic systems) is used to determine and define similarities and differences; to draw clear BOUNDARIES between 'us' and 'others'”' (p. 216, emphasis in original). Generally speaking, those who speak the dominant language or dialect are also the ones with the greatest distribution of power, as they belong to the dominant culture or majority. Brady (2015) notes that, in the United Kingdom, language and social class are intricately linked, with SE being seen as the most proper form of language, spoken by upper-class individuals at the 
time a standard English dialect was chosen. Carli et al. (2003) find that linguistic diversity is essential to ethnic and cultural identity, and diversity is also an essential element of defining power and status. Efforts are being made to maintain pride in different languages whose ethnolinguistic vitality may be threatened, or in groups whose identity and power may be at risk.

\section{Language Borrowing}

Different languages and dialects can be part of what separates groups from one another, creating a sense of identity and community within the different groups. According to SavilleTroike (2003), being fluent in a group's grammatical rules and vernacular is a cultural marker that signals an individual's membership within that social or ethnic group. This fluency functions as boundary maintenance, clearly demarcating the ingroup from the outgroup (Klippenstien, 2017). As languages grow and develop and members of different cultures and groups come in contact with each other, the process of linguistic borrowing and acquisition of loanwords can be expected, noted as possibly the most occurring product of cultural contact (Hoffer, 2002). It can be difficult to distinguish between borrowing and codeswitching, but a general criterion is that the use of a borrowed word is understood as codeswitching until enough speakers use it that it is accepted into the dictionary by native speakers. This is difficult to identify with the use of AAVE and LGBT slang terms within the dominant lexicon, as many slang terms do not make it into standard dictionaries. These dialects also are not considered to be foreign languages. However, members of groups that use AAVE or LGBT language are in frequent contact with members of the outgroup, who then hear these slang terms being used and begin to pick them up. This is not an example of the outgroup codeswitching, as they do not have a proficiency in the separate vernacular. 
As previously illustrated, American popular culture owes a great deal to other cultures, especially Black culture. Many popular things, from types of music to dance styles to fashion, can be traced back to a Black origin. Langston Hughes' (1940) "Notes on Commercial Theatre" focuses on the commodification of Black culture, particularly blues music; today, White rappers like Macklemore and Iggy Azalea re-spark the debate of what can be considered authentic (Heffernan, 2018). In response to the pervasiveness of White participation in Black cultural forms, rappers J. Cole and Azealia Banks draw comparisons to theft of Black cultural forms (Heffernan, 2018). There is a certain sense of irony from a society that appropriates Black culture, propelling the cultural forms to prominence especially when they are carried out by White individuals, but that gives the original Black culture negative connotations and holds negative impressions of Black individuals. Blackness is palatable to the masses when watered down or commodified, but there is a preponderance of representing Blackness as synonymous with criminality (Smiley \& Fakunle, 2016).

As language can help communicate an individual's identity, they may feel strong ties to others within their group that use the same dialect or speech patterns. When those from the outgroup begin to use these parts of language, not only does the original user begin to feel disassociated from their group and identity, but those from the outgroup can be more likely to not see the language as a marker of in and outgroup, resulting in identity gaps. The individual in the ingroup sees themselves clearly presenting as a member of a specific group due to their language use, while the member of the outgroup does not recognize the language as a presentation of group status, therefore not acknowledging the identity the speaker has put forth, creating a personal-relational identity gap. Because identity is so important to people, this can result in unfavorable outcomes where members of the ingroup feel distanced from the group, 
unrecognized in their identity, or members of the outgroup can be seen as insensitive by appropriating language that does not belong to them or their own groups.

\section{The Current Study}

Little research exists that explores the relationship between a person's intercultural tolerance and their likelihood to participate in the appropriation of another culture. However, someone with higher intercultural tolerance can be assumed to be better versed in the complexities of cultural appropriation versus appreciation, and would either be more likely to use terms from AAVE or LGBT language out of a sense of appreciation, or less likely to use the terms out of respect for other cultures. There is even less research done on LGBT tolerance, but similar conclusions are probable. It is important to contribute to the body of knowledge on these under-researched areas, as the problem of cultural appropriation is not going away; instead it is only becoming more relevant and pressing as time goes on. Similarly, no research exists on the likelihood of those from marginalized groups to participate in linguistic appropriation. It can be assumed that those who have experienced appropriation from their own culture would be less likely to take from another marginalized community, but it is also possible that appropriation is deeply ingrained within society to the point where the behavior is not noticed.

Research has shown that there are strong ties between an individual's language, including dialects, identity, and social power. Hegemonically, those that are a part of the dominant group or culture are likely to speak the dominant language or dialect and have the most social power. Individuals within the cultural majority also have the tendency to appropriate parts of other cultures that appeal to them, often refusing to give credit or recognize where the ideas come from once fully integrated into the majority. One such aspect is the constant appropriation of vocabulary or slang terms from AAVE and LGBT language. Once these terms are absorbed into 
the common lexicon, many individuals do not attempt to understand or appreciate the origins of many of the words they use. The appropriation of a culture or minority group's language can leave members of that group feeling cut off from their own language and part of their identity, potentially creating identity gaps between the four layers. With the influx of information sharing available and ever increasing due to the Internet, linguistic borrowing and appropriation can occur more quickly than ever. Clearly, the relationship between a person's identity and language is complex, and with the speed that linguistic appropriation can take place, the effects are more prevalent than ever. I want to contribute to this under-researched field by assessing the potential relationships between perceived acceptability of appropriation, intercultural tolerance, LGBT tolerance, and how CTI can be applied to these results. After reviewing the literature in relation to these topics, the research questions I have posed are:

$\mathrm{RQ}_{1}$ : For different demographic groups, what is the perceived acceptability of appropriation?

$\mathrm{RQ}_{2}$ : Is there a correlation between intercultural tolerance and the perceived acceptability of appropriation?

$\mathrm{RQ}_{3}$ : Is there a correlation between LGBT tolerance and the perceived acceptability of appropriation?

$\mathrm{RQ}_{4}$ : Is there a correlation between LGBT tolerance, intercultural tolerance, and slang tolerance?

\section{Conclusion}

This chapter serves first to illustrate the problem that many slang terms from AAVE or LGBT origins have been absorbed into the popular lexicon with little attempt to understand or appreciate the origins of these words by the members of the dominant group who then use them. 
This linguistic appropriation can often leave members of these groups feeling separated from their own language and therefore parts of their identities, potentially creating identity gaps between the layers found in CTI. While no current research exists that questions a connection between intercultural or LGBT tolerance and a person's willingness or likelihood to use appropriated slang terms, there is a strong possibility that a correlation does exist. Therefore, this study aims to identify any correlation between intercultural or LGBT tolerance and the likelihood of an individual using borrowed or appropriated slang terms. It also seeks to identify any correlation between LGBT, intercultural, and slang tolerance. 


\section{CHAPTER III: METHODS}

To study linguistic appropriation of slang in regard to CTI, an Acceptability of Appropriation scale was designed for the purposes of this study. Mendleson et al.'s (1997) Intercultural Tolerance scale and Logie et al.'s (2007) LGBT Assessment scale were also chosen to test participants. This chapter further outlines the methods, decisions, and research design of the study.

\section{Participants}

Participants were required to be at least 18 years old, attend a large Midwestern university, and be able to access an online survey to participate. Participants were recruited through the School of Communication research board at a large Midwestern university.

The sample consisted of 150 individuals, three of whom $(2.0 \%)$ chose not to answer the demographic questions at the end of the survey. The composition of the sample was $25.9 \%$ male, $73.5 \%$ female, and $.7 \%$ nonbinary. The mean age was $21.30(S D=3.88)$, ranging from 18 to 56 years old. Participants primarily self-identified as Caucasian/White (70.1\%), followed by African American (15.6\%), Hispanic (8.2\%), Other, (3.4\%), and Asian/Pacific Islander (2.7\%). The majority of the sample identified as heterosexual (91.1\%), followed by other (4.8\%), bisexual (3.4\%), and lesbian (.7\%). Educationally, the largest number of participants were Juniors (32.0\%), followed by First-year students (27.9\%), Seniors (27.2\%), Graduate students (9.5\%), and Sophomores (3.4\%).

\section{Data Collection}

\section{Procedures}

Participants completed an online survey, which was approved by the university's Institutional Review Board prior to distribution, through Qualtrics. All participants were 
informed of their rights prior to completing the survey and completed an informed consent form. The survey took about 20 minutes to complete.

\section{Measures}

The survey consisted of five sections. First there were sections to measure each of the following variables. There was then a demographic section asking for the participants' gender, age, race/ethnicity, sexual orientation, and year in school.

\section{Willingness to Appropriate}

Participants answered questions from the acceptability of appropriation scale, created for the purposes of the present study, containing three subscales for appropriateness, authorization, and desirability of appropriation based on Arewa's (2017) definition of appropriation. These all consisted of 5-point Likert scales, asking participants their level of agreement with the statements, from 1 (strongly disagree) to 5 (strongly agree).

\section{Tolerance Measures}

To assess participants' acceptance of LGBT individuals, the survey included Logie et al.'s (2007) LGBT assessment scale, previously developed through exploratory factor analysis and found to have good reliability. The final measure contained 22 items, arranged on a 5-point Likert scale, asking participants their level of agreement with the statements, from 1 (strongly disagree) to 5 (strongly agree) and had a good reliability $(\alpha=.79)$.

To measure tolerance for people of different ethnic identities, the survey included Mendleson et al.'s (1997) intercultural tolerance scale, previously developed through exploratory factor analysis and found to have good reliability. The scale included 32 items, measured in the same format as the LGBT assessment scale and had a very good reliability $(\alpha=.87)$. 
The survey also included a Slang Tolerance scale developed for the present study. The scale includes 10 items, measured in the same format as the LGBT assessment Scale.

Finally, participants answered a series of demographic questions. This included five items, measured in multiple-choice options, except for age, which was measured on a sliding scale.

\section{Data Analysis}

The acceptability of appropriation scale, comprised of three subscales, was created through exploratory factor analysis (EFA) of a set of questions with a common theme, using iterative reduction to drop questions with a primary factor loading below a .6 and maintaining secondary factor loadings at or below .4. The Kaiser-Meyer-Olkin (KMO) test was selected for extraction and Varimax rotation was used. The Slang Tolerance scale was also created through EFA of a set of questions with a common theme, using iterative reduction to drop questions with a factor loading below a .6 and maintaining secondary factor loadings at or below .4. The KMO test was also used for extraction. Some items from the phobia, attitude, slang tolerance, and intercultural tolerance scales were reverse coded so that all data could be measured similarly. The scales were then tested for reliability and then summed and averaged. Items for each scale were added together to create single measures for each of the key variables with the process guided through reliability analyses of each scale.

Due to low rates of participants that were not White and heterosexual, all other race and sexual orientation options were transformed into new variables by being collapsed into categories labeled non-White and non-heterosexual, and two independent samples $t$-tests were run to address RQ1. Bivariate correlations were run to answer RQ2 and RQ3, testing the correlation between intercultural tolerance and willingness to appropriate and LBGT tolerance 
and willingness to appropriate. A bivariate correlation was also run to test for significance between the different scales, answering RQ4.

\section{Conclusion}

This chapter describes the design of the research study. In order to answer the research questions, acceptability of appropriation and slang tolerance scales were developed for the study, and the study also included Mendleson et al.'s (1997) intercultural tolerance scale and Logie et al.'s (2007) LBGT assessment scale. After data were collected, two independent samples $t$-tests and three bivariate correlations were run. 


\section{CHAPTER IV: RESULTS}

After initial investigation into linguistic appropriation turned up little academic research and few studies, I devised the present study to observe any possible correlation between linguistic appropriation, intercultural tolerance, and LGBT tolerance, and how that may intersect with the identity gaps found within CTI. This chapter will articulate the findings of the previously explained research methods, organized by the different types of tests.

\section{Exploratory Factor Analyses}

The final exploratory factor analysis (EFA) procedure for the acceptability of appropriation scale produced an acceptable three-factor solution, but the third factor was dropped due to only having two items that did not have a clear relationship to one another. The KMO measure (.774) and Bartlett's test $\left[\chi^{2}=501.08(21), p<.001\right]$ were acceptable. Two factors had Eigenvalues that were greater than 1.00, as confirmed by the scree plot. The two-factor solution, where the first factor contained four items and the second factor contained three, collectively explained $63.94 \%$ of the variance. See Table 3 for the factor loadings.

The first factor explained $34.92 \%$ of the variance with a 2.44 eigenvalue, while the second factor explained $29.01 \%$ of the variance with a 2.03 eigenvalue. The first factor, labeled Authorized Use of Slang subscale, consisted of four items related to individuals' belief that the use of slang terms by someone not of the group or culture of origin should be authorized. The second factor, labeled Desirable Use of Slang subscale, consisted of three items related to individuals' belief that the use of slang terms by someone not of the group of culture of origin is viewed as desirable. The final two-factor solution produced an overall alpha coefficient reliability of .83. The subscales both produced very good reliabilities, with Authorized Use of Slang subscale $(\alpha=.86)$ and the Desirable Use of Slang subscale $(\alpha=.83)$. The scale as a whole, 
labeled Acceptability of Appropriation, was used to analyze participants' views towards using language that did not originate from the dominant culture or a culture that they belonged to, with a higher score indicating a greater agreement that language appropriation was acceptable.

\section{Table 3}

Factor Loadings for Acceptability of Appropriation Scale

\begin{tabular}{|c|c|c|}
\hline Survey Item & Authorized & Desirable \\
\hline $\begin{array}{l}\text { 1. I believe that the use of another group or culture's } \\
\text { slang should be authorized by members of said group. } \\
\text { [recoded] }\end{array}$ & .850 & .129 \\
\hline $\begin{array}{l}\text { 3. Using another group's slang is a pleasant use of } \\
\text { language. }\end{array}$ & .112 & .837 \\
\hline $\begin{array}{l}\text { 3. Using another group's dialect is something that should } \\
\text { be approved by members of said group. }\end{array}$ & .814 & -.014 \\
\hline $\begin{array}{l}\text { 2. I find it agreeable when people use slang from other } \\
\text { cultures. }\end{array}$ & .191 & .811 \\
\hline $\begin{array}{l}\text { 4. Using slang or a dialect from another group or culture } \\
\text { does not need to be approved by members of the group. } \\
\text { [recoded] }\end{array}$ & .731 & .286 \\
\hline 1. It is safe to use terms from another culture. & .142 & .682 \\
\hline $\begin{array}{l}\text { 2. I do not believe that the use of another group or } \\
\text { culture's slang should be authorized by members of said } \\
\text { group. }\end{array}$ & .677 & .329 \\
\hline Eigenvalue & 2.44 & 2.03 \\
\hline$\%$ of Variance & 34.92 & 29.01 \\
\hline Cronbach's alpha & .86 & .83 \\
\hline
\end{tabular}

Note. *Bolded numbers indicate which factor the item rotated onto.

The final EFA procedure for the Use of Slang scale produced an acceptable one-factor solution. Both the KMO measure (.665) and Bartlett's test $\left[\chi^{2}=153.519(3), \mathrm{p}<.001\right]$ were acceptable. One factor had eigenvalues above 1.00 , which was confirmed by the scree plot. The factor, labeled Use of Slang, consisted of three items related to individuals' usage and tolerance 
of slang. The one-factor solution, consisting of three items, explained $60.25 \%$ of the total variance with a 1.80 eigenvalue. The final single-factor solution produced very good reliability $(\alpha=.80)$. See Table 4 for factor loadings.

\section{Table 4}

Factor Loadings for Use of Slang Scale

Survey Item

1. I frequently use slang in my everyday life.

2. I do not use slang in my everyday life. [recoded]

3. I enjoy using a learning and using new slang terms.

\section{Tests of Difference}

In order to answer RQ1, two independent samples $t$-tests were run. First, an independent samples $t$-test was run to determine whether race affected one's willingness to appropriate. The Levene's test for variance was not significant $(F=.03, p=.84)$, so equality of variance can be assumed. Significant results were found, $t(145)=2.26, p=.02,95 \%$ CI $[-4.21,-.28]$. White participants' $(M=28.14, S D=5.57)$ willingness to appropriate scores significantly differed from those of participants who were not White $(M=25.89, S D=5.39)$. Therefore, White participants reported a higher likelihood to appropriate and engage in the use of language from a group they did not belong to than non-White participants. 
A second independent samples $t$-test was run to determine if sexual orientation affected one's willingness to appropriate. The Levene's test for variance was not significant $(F=.98, p=$ .32), so equality of variance can be assumed. Nonsignificant results were found, $t(144)=1.43, p$ $=.15,95 \% \mathrm{CI}[-.88,5.53]$. Heterosexual participants' $(M=27.71, S D=5.65)$ willingness to appropriate scores did not significantly differ from those of participants who were not heterosexual $(M=25.38, S D=4.72)$. Those participants that were heterosexual did not rate a higher likelihood to appropriate and engage in the use of language from a group they did not belong to than non-heterosexual participants.

\section{Correlations}

To answer RQ2, a bivariate correlation was run to assess the relationship between intercultural tolerance and willingness to appropriate. Intercultural tolerance demonstrated a moderate, negative association with willingness to appropriate, $r(145)=-.34, p<.001$. This means that the greater a participant's intercultural tolerance, the less likely they were to be willing to appropriate language from another culture. Another bivariate correlation was run to answer RQ3, assessing the relationship between LGBT tolerance and willingness to appropriate. A weak, negative association between the two was found: $r(145)=-.20, p=.01$. Similar to intercultural tolerance, the higher a participant's LGBT tolerance the less likely they were to willingly appropriate slang or language from a different culture. Finally, a bivariate correlation was run to assess any relationship between intercultural tolerance, LGBT tolerance, and slang tolerance to answer RQ4. A moderate, positive relationship was discovered between intercultural tolerance and LGBT tolerance, $r(145)=.55, p<.001$, as well as between intercultural tolerance and slang tolerance, $r(145)=.32, p<.001$. A weak correlation was present between LGBT tolerance and slang tolerance, $r(145)=.21, p=.008$. This illustrates that if someone has high 
intercultural tolerance, they are also likely to have high LGBT tolerance and slang tolerance. Those with high LGBT tolerance are somewhat likely to have high slang tolerance, but this connection was not as strong as that between intercultural tolerance and slang tolerance.

\section{Table 5}

Bivariate Correlations of Scaled Items

\begin{tabular}{lccccccc}
\hline Measure & $n$ & $M$ & $S D$ & 1 & 2 & 3 & 4 \\
\hline 1. Acceptability of & 147 & 27.46 & 5.60 & 1 & $-.348^{* *}$ & $-.204^{*}$ & -.063 \\
appropriation & & & & & & & \\
2. Intercultural tolerance & 150 & 112.47 & 14.86 & $-.348^{* *}$ & 1 & $.552^{* *}$ & $.326^{* *}$ \\
3. LGBT tolerance & 150 & 79.49 & 11.80 & $-.204^{*}$ & $.552^{*}$ & 1 & $.217^{* *}$ \\
4. Slang tolerance & 147 & 12.00 & 2.47 & -.063 & $.326^{* *}$ & $.217^{* *}$ & 1 \\
\hline \multicolumn{1}{c}{$* p<{ }^{* *} p<.01$} & & & & & &
\end{tabular}

\section{Conclusion}

This chapter serves to illustrate the findings of the chosen research methods and quantitative research tests. The two independent samples $t$-tests showed that White participants were more likely to engage in linguistically appropriative behaviors than non-White participants, while heterosexual participants were no more likely to engage in these behaviors than nonheterosexual participants. Bivariate correlations showed a negative correlation between intercultural tolerance and perceived acceptability of appropriation; a positive correlation between intercultural tolerance and LGBT tolerance; a positive correlation between intercultural tolerance and slang tolerance; and a weak positive correlation between LGBT tolerance and slang tolerance. 


\section{CHAPTER V: DISCUSSION}

To better understand the attitude towards groups and the willingness to appropriate their language, the acceptability of appropriation scale was designed for this study to be used in conjunction with Mendleson et al.'s (1997) intercultural tolerance scale and Logie et al.'s (2007)

LGBT assessment scale. The last chapter analyzed participants' survey answers through independent samples $t$-tests and bivariate correlations; the present chapter shall now examine these findings through the lens of CTI and draw conclusions accordingly.

\section{Summary of Findings}

RQ1 asked if there were different levels of perceived acceptability of appropriation within different demographic groups. Due to low participation from non-White, nonheterosexual respondents, the ethnicity and sexuality categories were collapsed into non-White and non-heterosexual categories instead of the original, more detailed breakdowns to be compared against the answers of White and heterosexual participants. The results of the independent samples $t$-tests showed that White participants scored significantly higher on the acceptability of appropriation scale and were thusly more likely to use appropriated language than their non-White counterparts. There was no significant difference between the scores of heterosexual and non-heterosexual participants.

RQ2 asked if a correlation existed between intercultural tolerance and the perceived acceptability of appropriation. The bivariate correlation showed a moderate negative association between the two, where the higher an individual scored on the intercultural tolerance scale, the lower they scored for perceived acceptability of appropriation. Thus, the more intercultural tolerance one demonstrates, the less likely they are to use appropriated language. Similarly, RQ3 asked if a correlation existed between LGBT tolerance and the perceived acceptability of 
appropriation. These demonstrated a weak negative correlation, where individuals who scored higher on the LGBT tolerance scale scored lower for perceived acceptability of appropriation.

Finally, RQ4 asked if any correlation existed between intercultural tolerance, LGBT tolerance, and slang tolerance. Moderate, positive correlations existed between intercultural tolerance and LGBT tolerance as well as intercultural tolerance and slang tolerance, and a mild correlation was present between LGBT tolerance and slang tolerance.

\section{Theoretical Implications}

As demonstrated within the literature review, little research on cultural and linguistic appropriation exists, especially within academic work. As a result, there seems to be a lack of statistics for comparison of the study's results. The first result, that White participants demonstrated a greater likelihood to appropriate language than non-White participants, was not surprising, though there was no discoverable academic research that predicted or supported these results. However, looking back at Wanner's (2016) definition of cultural appropriation, it is defined as "the taking of an original idea by members of a dominant group from a minority without acknowledgement, and insidiously refashioning it, so that said idea appears as if it had always belonged to the dominant group" (p. 78). In mainstream American culture, White people are the dominant group, so makes sense that they would be the ones more likely to appropriate language as well as any other aspects of culture. The examples of celebrities partaking in other

cultures frequently have something in common: Bieber, Madonna, Kloss, and Perry are all White (Cowles, 2012; Feeney, 2013; Lu, 2018; McFadden, 2016).

Revisiting CTI and identity gaps, identity gaps occur when there are discrepancies among the four frames of a person's identity (Hecht et al., 2005). These identity gaps can occur when people appropriate slang terms and begin to avow identities for themselves that may be 
unintentional. In general, linguistic appropriation does not negatively affect the identities of White communicators as they are the majority group. However, it could be argued that it creates a personal-enacted gap, where a person's enacted identity does not match how they view themselves as a communicator or person (Jung \& Hecht, 2004). When using appropriated slang, whether from AAVE or LGBT communities, a White communicator's view of themselves as White does not match their enacted identity of multi-racial or sexual linguistic behavior. This can create confusion and distance between them and those from the groups whose language they are appropriating, as they demonstrate a lack of understanding of the boundaries between groups, instead feeling as though they are welcome to participate within groups they do not belong to. White individuals using slang terms that are from groups they do not belong to or, in other words, the in group while they are members of the outgroup can also affect the linguistic community and its members. Specifically, in the case of AAVE, once a term leaves the Black community and is used in mainstream culture, being appropriated by nonblack users, it is often considered uncool and abandoned by its propagators (Grady, 2017). Those from the outgroup using these terms can also ascribe a sort of disposable trait to the ingroup and their language, while those from the ingroup see their language as a form of identity and a cultural marker. Thus, someone with lower intercultural competence who uses the group's language as an accessory does not show them that same level of respect.

Appropriation of slang terms by White people from non-White communities can also create personal-communal identity gaps in two potential ways. As a reminder, within the communal layer in CTI, groups affect identity, as members have comparable traits and form a group identity, and personal-communal identity gaps arise when an individual's view of themselves and their own identity does not match the group's. Specifically focusing on 
appropriation of slang terms from Black communities using AAVE, there is an inherent coolness identified with Black culture, and a desperation to posit oneself as part of the ingroup. As demonstrated in Lee's 1999 study, mainstream newspapers' frequent borrowing of terms originated in AAVE were at least in part due to an outgroup attempting to identify with an ingroup when "journalists attempt to create an image of 'coolness' and 'hipness' through the use of well-established or popular Black slang expressions" (p. 379). AAVE is the main source of lexical innovation on American Twitter and is the most important source for new slang that makes its way to SE (Grieve et al., 2018; Hill, 2008). When a White person uses slang terms that originated in AAVE, especially ones that have been reshaped and repurposed to better suit the new White users, they have crossed or attempted to cross into the Black community that created the terms to begin with (Hill, 2008). Members of the group, hearing someone who does not belong in the group using these terms whether incorrectly or not, may become confused or upset as the White individual is claiming membership. A person's view of themselves as a White individual, the personal layer, does not agree with the identity of the linguistic group they have attempted to align themselves with their enacted behavior, causing a personal-enacted-communal gap.

To the members of the ingroup, it can be offensive to have someone from the outgroup attempt to ascribe the group identity to themselves. According to Saville-Troike (2003), using an ethnically marked variety of a language, such as AAVE, in earnest typically requires being born into group membership; It is difficult to impossible to claim membership a different racial or sexual orientation group. Being fluent in a group's grammatical rules and vernacular functions as a cultural marker that signifies an individual's membership within that group that uses the ethnically marked variety of language, as illustrated by Willis' (1997) study of "Latino Night" at 
a bar in Northwest Ohio, where fluency or competence in Spanish was seen as a screen to shield participants from Anglos who were not willing to participate in good faith. The fluency functions as boundary maintenance, showing a clear delineation between ingroup and outgroup (Klippenstien, 2017). This is shown in regards to AAVE with multiple studies: Jacobs-Huey (1997) reported on a White graduate student who had a largely technically correct yet stereotyped usage of AAVE but was still seen as inauthentic by his Black peers; Cutler (2003) studied White hip-hoppers who contradicted their message of "keeping it real" within hip-hop by contributing to the erasure of blackness in the community and their adaptation of AAVE; and Eberhardt and Freeman (2015) found that White rapper Iggy Azalea overuses AAVE within her raps to position herself within the hip-hop community while using little to no AAVE within her everyday speech. This attempted entrance into the ingroup crosses a line when considered alongside language, power, and identity. Rivest et al. (2017) declare that language is as much a part of a person's identity as gender, race, and class. Not only can a White person create identity gaps by using appropriated slang, but they can further a power imbalance by using language that does not belong to them and alienating the original speakers, as shown by Hill's (2008) understanding of linguistic appropriation.

The research data show that the higher a person's intercultural tolerance, the less likely they are to use appropriated language, as well as the higher their LGBT tolerance, the less likely they are to use appropriated language. This shows that in general, the more informed a person is about other cultures and demographic groups, the less likely they are to perpetuate behaviors that may contribute to identity gaps and negatively influence the balance of linguistic power. Those with a higher intercultural competence, though they may appreciate the linguistic elements a 
group or culture has, will be less likely to adopt these elements as they see the pride that these groups have in their language, ascribing that pride and identity that those in the group avow.

\section{Practical Implications}

Although the results show that those with a higher interculture tolerance and LGBT tolerance are less likely to appropriate language, it is almost impossible to say that a person will never do so. Individuals need to be aware of the context in which they are using slang that may be appropriated, even if they feel they are using it in an appreciative sense. Because language is very personal, as shown by the ingroup/outgroup status it can bestow on a speaker, there can be a case-by-case basis of when or if the use of the language is acceptable. Individuals may ask themselves: am I close to people in the ingroup? Have I been welcomed into the group? Do the members of the group speak the language with me? If so, it may be permissible to use the slang interpersonally with those group members, as in Bernstein's (1964) idea of restricted code that draws on background knowledge, inside jokes, and shared understanding, usually used among family, close friends, and other groups. Removing this use from interpersonal interactions and instead using the terms in a more public forum like social media, where outgroup members can see and feel empowered to use the terms without having the close interpersonal relationships necessary for use, may be an abuse or appropriation of the terms. While still preliminary, the results of the study can be of use in places like classroom settings or workplace training, and any future research will also be applicable in these settings.

\section{Limitations}

Clearly, the largest limitation to this study was the lack of diversity within the participants, to where the categories within race and sexual orientation besides White and straight had to be collapsed in order to run tests with any hope of meaningful data. A larger 
sample size would potentially allow for a more diverse base of participants, especially if the sample were not solely drawn from a Midwestern university. A final limitation is simply that the nature of slang is that it is always changing, meaning that any study on the topic could potentially be obsolete by the time of completion (Zamaletdinova \& Izmaylova, 2016). Answers to the questions asked in the survey may be different now based on increased awareness of cultural appropriation and, more specifically, linguistic appropriation.

\section{Future Research}

The topic of linguistic appropriation needs further research. One topic that has become more relevant since the beginning of this study is that of digital blackface, both in GIF and audio format, the latter existing on TikTok. Digital blackface is described as "the odd and all-tooprevalent practice of White and non-Black people making anonymous claims to a Black identity through contemporary technological mediums such as social media” (Jackson, 2014, para. 5). The minstrelsy that exists on TikTok is different than other social media platforms: "TikTok is a video-first platform, and on it, creators embody Blackness with an auteur-driven virtuosity taking on Black rhythms, gestures, affects, slang" (Parham, 2020, para. 27). Applying the acceptability of appropriation scale to a study specifically focused on digital blackface and the unacknowledged appropriation that thrives on social media platforms would be an exciting next step in this research.

In the same vein, the ability to refine the questions on the acceptability of appropriation scale after this study and to further explore this topic with more nuance would also be a welcome next step. The acceptability of appropriation scale, especially with some more refinement, could be an important research tool that could be used in other research exploring different types of appropriation. While measuring participants' intercultural tolerance was a good preliminary 
measure, there are other possible factors to consider measuring when examining acceptability or willingness to appropriate: respect for other cultures, exposure to other cultures through travel, intersectionality, and possibly others. While creating the acceptability of appropriation scale was a good first step to measuring linguistic appropriation where a measure previously did not exist, the scale can be further validated by repeated tests. A potential direction for future research with the scale is to specifically test across non-dominant groups and see if the data change compared to this sample, which was overwhelmingly White, cisgendered females. Another important factor to consider is that this study only examined slang in general without considering that there are different types of slang or conditions where the usage of terms by members of the outgroup are more acceptable than others. For example, reclaimed slurs are generally seen as inappropriate for use by members of the outgroup, but this should be tested and confirmed. Open-ended surveying or focus groups could be used to gather and sort terms by type or overall acceptability of use by outgroup members. Overall, not only could this study be repeated with a more refined focus, but there are many opportunities to advance the limited base of research within the field of linguistic appropriation.

\section{Conclusion}

This study found that the higher a person's intercultural tolerance, the less likely they were to view appropriation of slang as acceptable, and a similar trend with LGBT tolerance. White participants were more likely than non-White participants to view appropriation of slang as acceptable. This usage of slang by White individuals can serve as an intrusion into cultural and linguistic groups that they do not belong to, causing personal-enacted, personal-communal, and personal-enacted-communal identity gaps. This can also be perceived as offensive or 
disrespectful to the ingroup, increasing the power imbalance between the linguistic majority and minority groups. 


\section{REFERENCES}

Admin. (2017, Nov. 16). Number of words in the English language: 1,057,379.6. The Global Language Monitor. https://www.languagemonitor.com/global-english/no-of-words/

Arewa, O. B. (2017). Love, hate, and culture wars. Phi Kappa Phi Forum, 97(1), 26-29.

Bereiter, C., \& Englemann, S. (1966). Teaching disadvantaged children in the preschool. Prentice-Hall.

Bernstein, B. (1964). Elaborated and restricted codes: Their social origins and some consequences. American Anthropologist, 66(6_PART2), 55-69. https://doi.org/10.1525/ aa.1964.66.suppl_3.02a00030

BlackPeopleTwitter. (n.d.). Reddit. https://www.reddit.com/r/BlackPeopleTwitter/

Bodle, A. (2016, Feb. 4). How new words are born. The Guardian. https://www.theguardian.com/media/mind-your-language/2016/feb/04/englishneologisms-new-words

Brady, J. (2015). Dialect, power and politics: Standard English and adolescent identities. Literacy, 49(3), 149-157. https://doi.org/10.1111/lit.12058

Brock, A. (2012). From the Blackhand side: Twitter as a cultural conversation. Journal of Broadcasting \& Electronic Media, 56(4), 529-549. https://doi.org/ $10.1080 / 08838151.2012 .732147$

Bucholtz, M. (1999). You da man: Narrating the racial other in the production of white masculinity. Journal of Sociolinguistics, 3(4), 443-460. https://doi.org/10.1111/1467-9481.00090 
Carli, A., Guardiano, C., Kaučič-Baša, M., Sussi, E., Tessarolo, M., \& Ussai, M. (2003). Asserting ethnic identity and power through language. Journal of Ethnic and Migration Studies, 29(5), 865-883. https://doi.org/10.1080/1369183032000149613

Carter, P. M. (2013). Shared spaces, shared structures: Latino social formation and African American English in the U.S. south. Journal of Sociolinguistics, 17, 66-92. https://doi.org/10.1111/josl.12015

Clark, H. H., \& Clark, E. V. (1977). Psychology and language: An introduction to psycholinguistics. Harcourt Brace Jovanavich.

Collier, M. J., \& Thomas, M. (1988). Cultural identity: An interpretive perspective. In Y. Y. Kim \& W. B. Gudykunst (Eds.), Theories in intercultural communication (pp. 99-120). Sage. Collins, S. (2015, June 30). Corporate giant Viacom to roll out gay cable channel tonight. The Baltimore Sun. http://articles.baltimoresun.com/2005-06-30/features/ 0506300101_1_viacom-gay-cable-network

Cowles, C. (2012, Nov. 12). Karlie Kloss, Victoria's Secret really sorry about that headdress. The Cut. https:/www.thecut.com/2012/11/karlie-kloss-really-sorry-about-thatheaddress.html

Crenshaw, K. (1991). Mapping the margins: Intersectionality, identity politics, and violence against women of color. Stanford Law Review, 43(6), 1241-1299. http://www.jstor.org/stable/1229039

Cultural appropriation: What is it and why is it so offensive? (2018, Sept. 4). The Week. http://www.theweek.co.uk/cultural-appropriation

Cutler, C. (1999). Yorkville Crossing: White teens, hip hop and African American English. Journal of Sociolinguistics, 3(4), 428-442. https://doi.org/10.1111/1467-9481.00089 
Cutler, C. (2003). “Keepin' it real”: White hip-hoppers' discourses of language, race, and authenticity. Journal of Linguistic Anthropology, 13(2), 1-23. https://doi.org/10.1525/jlin.2003.13.2.211

Denzin, N. K. (2004). Symbolic interactionism (B. Jenner, Trans.). In U. Flick, E. von Kardoff, \& I. Steinke (Eds.), A companion to qualitative research (pp. 81-87). Sage. (Original work published 2000).

Drake, D. (2014, April 22). Iggy Azalea’s “The New Classic” isn’t really. Complex. https://www.complex.com/music/2014/04/iggy-azalea-the-new-classic-review

Drummond, D. K., \& Orbe, M. P. (2009) “Who are you trying to be?”: Identity gaps within intraracial encounters. Qualitative Research Reports in Communication, 10(1), 81-87. https://doi.org/10.1080/17459430903236098

du Gay, P., Hall, S., Janes, L., Mackay, H., \& Negus, K. (1997). Doing cultural studies: The story of the Sony Walkman. Sage.

Dundes, A., \& Schonhorn, M. R. (1963). Kansas University slang: A new generation. American Speech, 38(3), 163-177. https://doi.org/10.2307/454096

Eberhardt, M., \& Freeman, K. (2015). "First things first, I'm the realest": Linguistic appropriation, white privilege, and the hip-hop persona of Iggy Azalea. Journal of Sociolinguistics, 19(3), 303-327. https://doi.org/10.1111/josl.12128

Elliot, A. (2017). On cultural appropriation and havens. CCPA Monitor, 24(2), 43. https://www.policyalternatives.ca/publications/monitor/cultural-appropriation-and-havens Ellis, D. G. (1999). From language to communication (2nd ed.). Routledge. 
Estrada, M. S. (2017, June 28). The fine line between cultural appropriation and appreciation. The Huffington Post. https://www.huffingtonpost.ca/meera-solanki-estrada/the-fine-linebetween-cultural-appropriation-and-appreciation_a_23004529/

Feeney, N. (2013, Nov. 25). Katy Perry's "geisha-style” performance needs to be called out. The Atlantic. https://www.theatlantic.com/entertainment/archive/2013/11/katy-perrys-geishastyle-performance-needs-to-be-called-out/281805/

Gopaldas, A. (2013). Intersectionality 101. Journal of Public Policy \& Marketing, 32(1_suppl), 90-94. https://doi.org/10.1509/jppm.12.044

Grady, C. (2017, Mar. 28). How “on fleek” went from a 16-year-old's Vine to the Denny's Twitter account. Vox. https:/www.vox.com/culture/2017/3/28/14777408/on-fleek-kaylalewis-ihop-dennys-vine-twitter-cultural-appropriation

Grieve, J., Nini, A., \& Guo, D. (2018). Mapping lexical innovation on American social media. Journal of English Linguistics, 46(4), 293-319. https://doi.org/10.1177/ 0075424218793191

Gulati-Partee, G., \& Potapchuk, M. (2014). Paying attention to White culture and privilege: A missing link to advancing racial equity. The Foundation Review 6(1), 25-38. https://doi.org/10.9707/1944-5660.1189

Hecht, M. L. (1993). 2002—a research odyssey: Toward the development of a communication theory of identity. Communication Monographs, 60(1), 76-82. https://doi.org/ $10.1080 / 03637759309376297$

Hecht, M. L., Collier, M. J., \& Ribeau, S. A. (1993). African American communication: Ethnic identity and cultural interpretation. Sage. 
Hecht, M. L., Jackson, R. L., \& Pitts, M. J. (2005). Culture: Intersections of intergroup and identity theories. In J. Harwood \& H. Giles (Eds.), Intergroup communication: Multiple perspectives (pp. 21-42). Peter Lang.

Hecht, M. L., Warren, J. R., Jung, E., \& Krieger, J. L. (2005). The communication theory of identity: Development, theoretical perspective, and future directions. In W. Gudykunst (Ed.), Theorizing about intercultural communication (pp. 257-278). Sage.

Heffernan, N. (2018). “As usual, I'll have to take an IOU”: W. E. B. Du Bois, the gift of Black music and the cultural politics of obligation. Journal of American Studies, 52, 1095-1121. https://doi.org/10.1017/S0021875817000883

Hill, J. H. (2008). The everyday language of White racism. Wiley-Blackwell. https://doi.org/ $10.1002 / 9781444304732$

Hoffer, B. L. (2002). Language borrowing and language diffusion: An overview. Intercultural Communication Studies, 11(4), 1-37. https://web.uri.edu/iaics/files/01-Bates-L.Hoffer.pdf

hooks, b. (1992). Eating the other: Desire and resistance. In b. hooks (Ed.), Black looks: Race and representation (pp. 21-39). South End Press. https://doi.org/10.4324/9781315743226

Hughes, L. (1940). Note on commercial theatre. https://www.poetrynook.com/poem/notecommercial-theatre

Jackson, L. M. (2014, Aug. 28). Memes and misogynoir. The Awl. https://www.theawl.com/ 2014/08/memes-and-misogynoir/

Jacobs-Huey, L. (1997). Is there an authentic African American speech community: Carla revisited. U. Penn Working Papers in Linguistics, 4, 331-370. https://repository.upenn.edu/cgi/viewcontent.cgi? article $=1618 \&$ context=pwpl 
Jasmine Masters. (2017, Apr. 7). Jasmine Masters the meaning of Jush [Video]. Youtube. https://www.youtube.com/watch?v=39BWUUE72Sg

Jin, H. (2017). Existing approaches of cultural studies and global dialogism: A study beginning with the debate around "cultural imperialism." Critical Arts: A South-North Journal of Cultural \& Media Studies, 31, 34-48. https://doi.org/10.1080/02560046.2017.1290666

Johnson, F. L. (2000). Speaking culturally: Language diversity in the United States. Sage. https://www.doi.org/10.4135/9781452220406

Johnson, M. Z. (2015, June 14). What's wrong with cultural appropriation? These 9 answers reveal its harm. Everyday Feminism. https://everydayfeminism.com/2015/06/culturalappropriation-wrong/

Jones, D. (2017, Mar. 1). "Lip Sync Battle” is just a watered-down version of drag culture. Vice. https://noisey.vice.com/en_ca/article/qkm4mv/lip-sync-battle-watered-down-versiondrag-queer-culture

Jung, E. (2013). Delineation of a threefold relationship among communication input variables, identity gaps, and depressive symptoms. Southern Communication Journal, 78(2), 163 184. https://doi.org/10.1080/1041794X.2012.741652

Jung, E. A. (2016, Mar. 23). Real talk with RuPaul. Vulture. http://www.vulture.com/2016/03/ rupaul-drag-race-interview.html

Jung, E., \& Hecht, M. L. (2004). Elaborating the communication theory of identity: Identity gaps and communication outcomes. Communication Quarterly, 52(3), 265-283. https://doi.org/10.1080/0146337040937019 
Jung, E., \& Hecht, M. L. (2008). Identity gaps and level of depression among Korean immigrants. Health Communication, 23, 313-335. https://doi.org/10.1080/10410230802229688

Klippenstein, K. (2017). Language appropriation and identity construction in new religious movements: Peoples Temple as a test case. Journal of the American Academy of Religion, 85(2), 348-380. https://doi.org/10.1093/jaarel/lfw082

Kreps, D. (2014, Nov. 22). Jimmy Fallon's “Lip Sync Battle” gets spinoff TV show. Rolling Stone. https://www.rollingstone.com/tv/tv-news/jimmy-fallons-lip-sync-battle-getsspinoff-tv-show-165772/

Labov, W. (2003). Unendangered dialect, endangered people: The case of African American Vernacular English. Transforming Anthropology, 18, 15-27. https://doi.org/10.1111/j.1548-7466.2010.01066.x.

Lee, M. (1999). Out of the hood in and into the news: Borrowed Black verbal expressions in a mainstream newspaper. American Speech, 74(4), 369-388. http://www.jstor.org/ stable/455663

Linnes, K. (1998). Middle-class AAVE versus middle-class bilingualism: Contrasting speech communities. American Speech, 73(4), 339-367. https://doi.org/10.2307/455582

Logie, C., Bridge, T. J., \& Bridge, P. D. (2007). Evaluating the phobias, attitudes, and cultural competence of Master of Social Work students toward the LGBT populations. Journal of Homosexuality, 53(4), 201-221. https://doi.org/10.1080/00918360802103472

LSPIRG. (n.d.). I am not a costume. http://www.lspirg.org/costumes/ 
Lu, J. (2018, Aug. 21). The story behind Madonna's silver horns at the VMAs. National Public Radio. https://www.npr.org/sections/goatsandsoda/2018/08/21/640587899/the-storybehind-madonnas-silver-horns-at-the-vmas

Luckmann, T. (2013). The communicative construction of reality and sequential analysis. A personal reminiscence. Qualitative Sociology Review, 9(2), 40-46. http://www.qualitativesociologyreview.org/ENG/volume25.php

Luu, C. (2018, June 6). The unspeakable linguistics of camp. Lingua Obscura. https://daily.jstor.org/unspeakable-linguistics-camp/

Mattiello, E. (2005). The pervasiveness of slang in standard and non-standard English. Mots Palabras Words, 6, 7-41. http://www.ledonline.it/mpw/allegati/mpw0506Mattiello.pdf

McFadden, S. (2016, Apr. 5). Justin Bieber's dreadlocks: What he should learn about locked hair. The Guardian. https://www.theguardian.com/fashion/2016/apr/05/justin-bieberdreadlocks-cultural-appropriation-black-pride

Mendleson, J. L., Bures, A. L., Champion, D. L., \& Lott, J. K. (1997). Preliminary development of the intercultural tolerance scale. Psychological Reports, 80, 867-876. https://doi.org/10.2466/pr0.1997.80.3.867

Mercado, M. (2017, May 30). 7 things you might not realize are cultural appropriation that are. Bustle. https:/www.bustle.com/p/7-things-you-might-not-realize-are-culturalappropriation-that-are-60679

Merriam-Webster. (2018). How to 'zhuzh' up your vocabulary. https://www.merriamwebster.com/words-at-play/zhuzh-zhoosh-queer-eye-origin-kressley 
Miz Cracker. (2015, Aug. 13). Beware the bachelorette! A report from the straight lady invasion of gay bars. Slate. http://www.slate.com/blogs/outward/2015/08/13/ should_straight_women_go_to_gay_bars_a_drag_queen_reports_on_the_lady_invasion.h tml

Mufwene, S. S. (2017). Language vitality: The weak theoretical underpinnings of what can be an exciting research area. Language, 93(4), 202-223. https://doi.org/10.1353/lan.2017.0065

Nicholas, C. (2006). Disciplinary-interdisciplinary GLBTQ (identity) studies and Hecht's layering perspective. Communication Quarterly, 54(3), 305-330. https://doi.org/10.1080/01463370600878107

Norton, B. (1997). Language, identity, and the ownership of English. TESOL Quarterly, 31(3), 409-429. https://doi.org/10.2307/3587831

Orbe, M. P. (2004). Negotiation multiple identities within multiple frames: An analysis of firstgeneration college students. Communication Education, 53(2), 131-149. https://doi.org/10.1080/03634520410001682401

Pandell, L. (2018, Mar. 22). How RuPaul's Drag Race fueled pop culture's dominant slang engine. Wired. https://www.wired.com/story/rupauls-drag-race-slang/

Parham, J. (2020, Aug. 4). TikTok and the evolution of digital blackface. Wired. https://www.wired.com/story/tiktok-evolution-digital-blackface/

Petski, D. (2017, Mar. 27). RuPaul's Drag Race draws nearly 1M viewers in VH1 debut. Deadline. https://deadline.com/2017/03/rupauls-drag-race-ratings-records-1-millionviewers-season-9-premiere-vh1-1202053113/ 
Rassool, N. (1998). Postmodernity, cultural pluralism and the nation-state: Problems of language rights, human rights, identity and power. Language Sciences, 20(1), 89-99. https://doi.org/10.1016/s0388-0001(97)00014-4

Rickford, J. R., \& Rickford, R. J. (2000). Spoken soul: The story of Black English. John Wiley \& Sons.

Riley, A. R., \& Carpenter, K. A. (2016). Owning Red: A theory of Indian (cultural) appropriation. Texas Law Review, 94, 859-931. https://doi.org/10.31228/osf.io/zbnuc

Rivest, M. P., Moreau, N., \& Negura, L. (2017). From affirmed privilege to experiences of discrimination: Majority Anglophones’ perceptions of linguistic majority-minority dynamics in Canada. Canadian Ethnic Studies, 49(1), 67-84. https://doi.org/10.1353/ces.2017.0003

Rogers, J. (2006). From cultural exchange to transculturation: A review and reconceptualization of cultural appropriation. Communication Theory, 16(4), 474-503. https://doi.org/10.1111/j.1468-2885.2006.00277.x

Saturday Night Live. (2017, May 6). Auto shop - SNL [Video]. Youtube. https://www.youtube.com/watch?v=QFtNS52ueQs\&frags $=$ pl $\% 2 \mathrm{Cwn}$ Saturday Night Live. (2018, Apr. 14). Drag brunch - SNL [Video]. Youtube. https://www.youtube.com/watch?v=6mtkqIrOLOg Saville-Troike, M. (2003). The ethnography of communication: An introduction (3rd ed.). Blackwell. https://doi.org/10.1002/9780470758373

Shand, P. (2002). Scenes from the colonial catwalk. Cultural Analysis, 3, 47-88. https://www.ocf.berkeley.edu/ culturalanalysis/volume3/vol3_article3.html 
Shaw, S. (2017, June 26). Bachelorette parties, drag, and the appropriation of queer space. The Huffington Post. https://www.huffingtonpost.com/entry/bachelorette-parties-drag-andthe-appropriation-of_us_59514f35e4b0c85b96c65b93

Shorey, E. (2017, Dec. 5). Read our lips: On the power of and meaning behind lip syncing. Nylon. https://nylon.com/articles/semiotics-lip-syncing-drag-queens

Sicha, C. (2009, Nov 11). What were Black people talking about on Twitter last night? The Awl. https://medium.com/the-awl/what-were-black-people-talking-about-on-twitter-last-night$4408 \mathrm{ca} 0 \mathrm{ba} 3 \mathrm{~d} 6$

Simes, G. (2005). Gay slang lexicography: A brief history and a commentary on the first two gay glossaries. Dictionaries: Journal of the Dictionary Society of North America, 26(1), 1159. https://doi.org/10.1353/dic.2005.0004

Smiley, C., \& Fakunle, D. (2016). From "brute" to "thug:" The demonization and criminalization of unarmed Black male victims in America. Journal of Human Behavior in the Social Environment, 26(3-4), 350-366. https://doi.org/10.1080/10911359.2015.1129256

Sweetland, J. (2002). Unexpected but authentic use of an ethnically-marked dialect. Journal of Sociolinguistics, 6(4), 514-536. https://doi.org/10.1111/1467-9481.00199

Taylor, O. L. (1998). Ebonics and education policy: Some issues for the next millennium. The Journal of Negro Education, 67, 35-42. https://doi.org/10.2307/2668238

Tran, K. (2016, May 2). 5 simple questions that'll help you avoid unintentional cultural appropriation. Everyday Feminism. https://everydayfeminism.com/2016/05/avoidcultural-appropriation/ 
Turner, K. (2015, June 29). Pretty much everything we say comes from the world of drag queens. Mic. https://mic.com/articles/121464/rupauls-drag-race-shade-yaaasssvocabulary\#.gFGQbYdg1

Uwujaren, J. (2013, Sept. 30). The difference between cultural exchange and cultural appropriation. Everyday Feminism. https://everydayfeminism.com/ 2013/09/culturalexchange-and-cultural-appropriation/

Wadsworth, B. C., Hecht, M. L., \& Jung, E. (2008). The role of identity gaps, discrimination, and acculturation in international students' educational satisfaction in American classrooms. Communication Education, 57(1), 64-87. https://doi.org/10.1080/03634520701668407

Walsh, K. (2017, May 18). On Lip Sync Battle, the lip syncing gets lost in the fog. Slate. http://www.slate.com/blogs/browbeat/2017/05/18/it_s_time_for_lip_sync_battle_to_sash ay_away.html

Wanner, Z. (2016). The trouble with cultural appropriation. New African, 566, 78-79.

Wheeler, R. S., \& Swords, R. (2004). Codeswitching: Tools of language and culture transform the dialectally diverse classroom. Language Arts, 81(6), 470-480. https://cdn.ncte.org/ nctefiles/pd/consulting/wheelerlajuly2004.pdf

Whitney, J. (2005). Five easy pieces: Steps towards integrating AAVE into the classroom. The English Journal, 94(5), 64-69. https://doi.org/10.2307/30047356

Whitman, W. (1885). Slang in America. The North American Review, 141(348), 431-435. https://www.jstor.org/stable/25118543

Willis, J. L. (1997). "Latino night”: Performances of Latino/a culture in Northwest Ohio. Communication Quarterly, 45(3), 335-354. https://doi.org/10.1080/01463379709370070 
Wodak, R. (2012). Language, power and identity. Language Teaching, 45(2), 215-233. https://doi.org/10.1017/s0261444811000048

Young, J. O. (2005). Profound offense and cultural appropriation. Journal of Aesthetics \& Art Criticism, 63(2), 135-146. https://doi.org/10.1111/j.0021-8529.2005.00190.x

Young, J. O. (2008). Cultural appropriation and the arts. Blackwell. https://doi.org/10.1002/9780470694190

Young, J. O., \& Haley, S. (2009). "Nothing comes from nowhere”: Reflections on cultural appropriation as the representation of other cultures. In J. O. Young \& C. G. Brunk (Eds.), The ethics of cultural appropriation. Blackwell. https://doi.org/ $10.1002 / 9781444311099$

Zamaletdinova, G. R., \& Izmaylova, G. A. (2016). Features of youth slang functioning. International Journal of Humanities and Cultural Studies. http://www.ijhcs.com/ index.php/ijhcs/article/view/2630

Zhang, L., Zhau, J., \& Xu, K. (2016). Who creates trends in online social media: The crowd or opinion leaders? Journal of Computer-Mediated Communication, 21, 1-16. https://doi.org/10.1111/jcc4.12145

Ziff, B., \& Rao, P. V. (1997). Introduction to cultural appropriation: A framework for analysis. In B. Ziff \& P. V. Rao (Eds.), Borrowed power: Essays on cultural appropriation (pp. 127). Rutgers University Press. 


\section{APPENDIX: SURVEY ITEMS}

For each question below, select the number that best fits your response. Unless otherwise stated, all questions are evaluated on a Likert scale, with response options from 1 (strongly disagree) to 5 (strongly agree).

Intercultural Tolerance Scale Items

1. I enjoy hearing different languages spoken.

2. Generally, our society is made richer and stronger by the diversity of all its immigrants.

3. If I move to another country to work there, I would wear their type of clothing, no matter how different from my own.

4. I would not like to work in a foreign country where the religious beliefs were contrary to my own.

5. The news about my country is more important than the news about any other nations.

6. The best way to improve economic conditions in underdeveloped nations is to teach them to do things the way they are done in my country.

7. Giving a personal gift to make a business deal is okay when doing business in a country where such a gift is common practice.

8. I think the social custom of having kings, queens, chiefs, or other royalty is outdated.

9. I do not care to speak any language other than my own.

10. Many economic problems of my country have been caused by undesired immigrants.

11. I am offended by foreigners who continue to wear their native clothing while living and working in my country.

12. I would like to learn more about religious beliefs and practices in foreign cultures.

13. World interests are more important than the interests of my country.

14. We should be willing to temporarily lower our standard of living if it would improve the long-term standard of living for all citizens of the world.

15. Avoiding "the facts" in order to "save face" as practiced in some Eastern cultures is a valid approach to conflict.

16. The practice of women not shaving their legs, as found in some cultures, is repulsive to me.

17. I would prefer to see all languages of the world continue to be used.

18. Immigration to my country should be stopped because there are already enough foreigners living here.

19. If I visited other countries, I would welcome the opportunity to sample different types of food.

20. Holidays should be chosen to accommodate the beliefs of all religious groups in my country.

21. The form of government in my country is superior to that of most countries in the world. 
22. Rich countries should share their technological resources, especially nonmilitary, with poor countries.

23. My country's work ethic is superior to that of most other countries.

24. While visiting a foreign country I would like to experience the local social environment.

25. Foreigners living or working in this country should use our language, rather than continue to use their own language.

26. I would enjoy working with coworkers who are from other countries.

27. I don't think I would like to eat in the home of persons from a foreign country.

28. I think the world would be better off if everyone practiced my religion.

29. I would be willing to live and work in a foreign country which has a different form of government from my own.

30. Economic exploitation of some countries by other countries is necessary and justified in order for the world to continue to advance.

31. Societies which emphasize traditional practices over modern practices are behind the times.

32. I think the foreign custom of greeting other people, males and females, with a kiss on each cheek, is okay.

Phobia Scale

1. I would feel comfortable working closely with a gay man.

2. Bisexual people are just as moral as heterosexuals.

3. I would feel that I had failed as a parent if I learned that my child was transgendered.

4. Homosexuality is a sin.

5. Transgender people live an immoral lifestyle.

6. I would feel comfortable working closely with a lesbian.

7. I would feel that I had failed as a parent if I learned my child was gay or lesbian.

8. Bisexuality is a sin.

9. Homosexual people are just as moral as heterosexuals.

10. I would feel comfortable working closely with a transgender person.

11. I would feel that I had failed as a parent if I learned that my child was bisexual.

12. Transgender people are sinful.

13. I would feel comfortable working closely with a bisexual person.

Attitude Scale

1. If a person has homosexual feelings, they should do everything to overcome these feelings.

2. Bisexuality is merely a different kind of lifestyle that should not be condemned.

3. Homosexuality is merely a different kind of lifestyle that should not be condemned. 
4. Bisexuality is a threat to many of our basic social institutions.

5. If a person feels that they belong to a different gender than the one they were born into, they should do everything to overcome these feelings.

6. Transgender people threaten many of our basic social institutions.

7. If a person has bisexual feelings, they should do everything to overcome these feelings.

8. Homosexuality is a threat to many of our basic social institutions.

9. Transgender people merely have a different sexual identity that should not be condemned.

Slang Scale

1. I frequently use slang in my everyday life.

2. I do not use slang in my everyday life.

3. Slang is appropriate for casual conversations, but not in the workplace.

4. I do not believe that most people use slang every day.

5. I don't know most slang terms that people use around me.

6. I'm very familiar with most popular slang terms.

7. Slang is appropriate in most conversations.

8. It annoys me when people use slang frequently around me.

9. I enjoy learning and using new slang terms.

10. I believe that intelligent people use slang terms frequently.

Sometimes slang originates from a historically marginalized culture and is then popularized and used by the majority. For each question below, select the number that best fits your response. Unless otherwise stated, all questions are evaluated on a Likert scale, with response options from 1 (strongly disagree) to 5 (strongly agree).

Appropriateness Scale

1. It is inappropriate when someone uses terms from another culture

2. I consider it appropriate when someone uses terms from another culture

3. It is improper to use slang that originated in another culture

4. It is proper to use slang that originated in another culture

5. Using another group's slang is a proper use of language

6. It is an improper use of language to use slang from another culture.

\section{Authorization Scale}

1. I believe that use of another group or culture's slang should be authorized by members of said group

2. I do not believe that use of another group or culture's slang should be authorized by members of said group

3. Using another group's dialect is something that should be approved by members of said group. 
4. Using slang or a dialect from another group or culture does not need to be approved by members of the group.

5. It is permissible for someone to use slang from a group that they do not belong to.

6. It is impermissible for someone that does not belong to a certain group to use language from said group.

Desirability Scale

1. It is safe to use terms from another culture

2. I find it agreeable when people use slang from other cultures

3. Using another group's slang is a pleasant use of language

4. It is inadvisable to use another group's slang.

5. It is disagreeable to use language from another culture

6. It could be seen as hurtful to use slang from another culture.

\section{Demographic Questions}

1. What is your gender? (Male, Female, Transgender, Nonbinary)

2. What is your age?

3. What is your race/ethnicity? (African American, Native American, Caucasian, Hispanic, Biracial/Mixed race, Asian/Pacific Islander, Other)

4. What is your sexual orientation? (Heterosexual, Gay, Lesbian, Bisexual, Other)

5. What is your year in school? (First-year, Sophomore, Junior, Senior, Graduate student) 